Article

\title{
Development of a CALPHAD Thermodynamic Database for Pu-U-Fe-Ga Alloys
}

\author{
Emily E. Moore ${ }^{1, *}$, Patrice E.A. Turchi ${ }^{1}$, Alexander Landa ${ }^{1}$, Per Söderlind ${ }^{1}$, Benoit Oudot ${ }^{2}$, \\ Jonathan L. Belof ${ }^{1}$, Stephen A. Stout ${ }^{1}$ and Aurélien Perron ${ }^{1, *}$ \\ 1 Lawrence Livermore National Laboratory, 7000 East Avenue, Livermore, CA 94550, USA; \\ turchi1@llnl.gov (P.E.A.T.); landa1@llnl.gov (A.L.); soderlind1@llnl.gov (P.S.); belof1@1lnl.gov (J.L.B.); \\ stout18@llnl.gov (S.A.S.) \\ 2 CEA-Centre de Valduc, 21120 Is sur Tille, France; benoit.oudot@cea.fr \\ * Correspondence: moore255@llnl.gov (E.E.M.); perron1@llnl.gov (A.P.)
}

Received: 11 October 2019; Accepted: 15 November 2019; Published: 22 November 2019

\begin{abstract}
The interaction of actinides and actinide alloys such as the $\delta$-stabilized Pu-Ga alloy with iron is of interest to understand the impurity effects on phase stability. A newly developed and self-consistent CALPHAD thermodynamic database is presented which covers the elements: $\mathrm{Pu}, \mathrm{U}, \mathrm{Fe}$, $\mathrm{Ga}$ across their whole composition and temperature ranges. The phase diagram and thermodynamic properties of plutonium-iron ( $\mathrm{Pu}-\mathrm{Fe})$ and uranium-iron (U-Fe) systems are successfully reassessed, with emphasis on the actinide rich side. Density functional theory (DFT) calculations are performed to validate the stability of the stoichiometric $(\mathrm{Pu}, \mathrm{U})_{6} \mathrm{Fe}$ and $(\mathrm{Pu}, \mathrm{U}) \mathrm{Fe}_{2}$ compounds by computing their formation enthalpies. These data are combined to construct the Pu-U-Fe ternary phase diagram. The thermodynamic assessment of Fe-Ga is presented for the first time and application to the quaternary $\mathrm{Pu}-\mathrm{U}-\mathrm{Fe}-\mathrm{Ga}$ system is discussed.
\end{abstract}

Keywords: actinides; CALPHAD; impurities; thermodynamics; plutonium-alloys

\section{Introduction}

The interest in actinide elements is due to their complex physics and extends across many nuclear applications; specifically, plutonium and uranium, that are studied by various government entities, largely to focus on energy production. In that context, the phase stability with respect to chemical composition and temperature is paramount to understanding actinide materials behavior under normal, extended/aging and off-normal (accident) conditions. In this work, the focus lies in the effects of iron (a common impurity) on actinide (An) phase stability. In general, Fe has limited solubility in the actinides themselves, but can easily form the stoichiometric composition $\mathrm{Pu}_{6} \mathrm{Fe}$ and $\mathrm{U}_{6} \mathrm{Fe}$, in addition to higher iron containing compounds $\left(\mathrm{PuFe}_{2}\right.$ and $\left.\mathrm{UFe}_{2}\right)$. Since experiments can be rather tedious and expensive for actinide systems, computational models, such as the CALPHAD method is applied. Emphasis on $\mathrm{Pu}$ alloys with $\mathrm{Ga}$ acting as $\delta$-stabilizer (fcc phase of plutonium) and $\mathrm{U}$ acting as a transmutation product are studied across potential composition and temperature ranges to elucidate phase relations with Fe acting as an impurity. Except for the Fe-Ga system, the binary systems included in this study of the Pu-U-Fe-Ga system have been extensively characterized in experiment (see literature review below) and preliminary thermodynamic models exist in the literature [1-7]: Pu-U [1], Pu-Fe [2,3], Pu-Ga [1], U-Fe [3,4], U-Ga [5,6], Fe-Ga [7].

As the focus is on small amounts of iron (to model impurity effects) this work aims to improve the currently accepted models of Pu-Fe and U-Fe of [3], especially on the actinide-rich side. Current shortcomings include little to no solubility of iron in the Pu allotropic phases as well as a neglect of the catatectic reaction described in the Pu-Fe section below. The liquidus on the Pu-rich side is also refined. 
Similarly, the solubility of iron in tetragonal uranium $(\beta-U)$ is not well described in the currently accepted model and overall improvements in the accuracy of the invariant reactions is achieved. The new CALPHAD assessments are supported by density-functional-theory (DFT) electronic-structure calculations (i.e., enthalpy of formation of compounds). Finally, this paper includes the first attempt at modeling the Fe-Ga and An-Fe-Ga systems (with $\mathrm{An}=\mathrm{Pu}, \mathrm{U}$ ).

\section{Thermodynamic Modeling}

\subsection{CALPHAD Method}

Computational Thermodynamics in the form of the CALculation of PHAse Diagrams (CALPHAD) method provides self-consistent Gibbs energy functions, for a given phase and/or structure [8], which are used to calculate equilibrium conditions of multicomponent systems. The model parameters are optimized using critically selected thermochemical and constitutive data as input. For the pure elements, the data from the SGTE [9] database is used and is expressed via the following temperature ( $\mathrm{T}$ in $\mathrm{K}$ ) dependent function, for element, $\mathrm{x}$ in a given phase, $\phi$ :

$$
{ }^{0} \mathrm{G}_{\mathrm{x}}^{\phi}=\mathrm{G}^{\Phi}-\mathrm{H}_{\mathrm{x}}^{\mathrm{SER}}=\mathrm{a}+\mathrm{bT}+\mathrm{cT} \ln (\mathrm{T})+\mathrm{dT}^{2}+\mathrm{eT}^{3}+\mathrm{fT}^{-1}+\mathrm{g}_{\mathrm{n}} \mathrm{T}^{\mathrm{n}}
$$

In the above expression, $\mathrm{H}_{\mathrm{x}}^{\mathrm{SER}}$ is the molar enthalpy of component $\mathrm{x}$ in its standard element reference (SER) state at $298.15 \mathrm{~K}$ and $10^{5} \mathrm{~Pa}$. In the case of the elements described here, the standard states are $\alpha$-U (orthorhombic), $\alpha$-Fe (body centered cubic), $\alpha$-Ga (orthorhombic) and $\alpha$-Pu (simple monoclinic), where crystallographic structures are detailed in Table 1. The following phases: $\alpha-U$, $\alpha-\mathrm{Pu}, \beta-\mathrm{Pu}, \gamma-\mathrm{Pu}$ and $\delta^{\prime}-\mathrm{Pu}$ are treated as fixed compositions (neglecting solubility) and represented using (Equation (1)). The liquid, bcc ( $\alpha-\mathrm{Fe}, \delta$-Fe, $\varepsilon-\mathrm{Pu}, \gamma-\mathrm{U})$, fcc $(\gamma-\mathrm{Fe}, \delta-\mathrm{Pu})$ and $\beta$-U are all treated as solution phases and are modelled as substitutional solutions yielding the following molar Gibbs energy expression for a given phase $\phi$ :

$$
\mathrm{G}_{\mathrm{m}}^{\phi}=\sum_{\mathrm{i}} \mathrm{x}_{\mathrm{i}}^{0} \mathrm{G}_{\mathrm{i}}^{\phi}+\mathrm{RT} \sum_{\mathrm{i}} \mathrm{x}_{\mathrm{i}} \ln \left(\mathrm{x}_{\mathrm{i}}\right)+{ }^{\text {phys }} \mathrm{G}_{\mathrm{m}}^{\phi}+{ }^{\mathrm{E}} \mathrm{G}_{\mathrm{m}}^{\phi}
$$

where the first term represents the mechanical mixing of the end-members $\left({ }^{0} \mathrm{G}_{i}^{\phi}\right.$ are the Gibbs energies of the pure elements in the structural state $\phi$ ), the second term represents the contribution due to the ideal entropy of mixing, the third includes physical models such as magnetic contribution and the fourth term ( ${ }^{\mathrm{ex}} \mathrm{G}_{\mathrm{m}}^{\phi}$ ) represents the excess molar Gibbs energy.

For phases with order-disorder transformations (e.g., bcc_A2/B2), the partitioning model is used, which means the ordering is described as an addition to the Gibbs energy of the disordered phase so that the molar Gibbs energy is described as:

$$
\mathrm{G}_{\mathrm{m}}^{\mathrm{bcc}}=\mathrm{G}_{\mathrm{m}}^{\mathrm{dis}}+\Delta \mathrm{G}_{\mathrm{m}}^{\text {ord }}
$$

where $G_{m}^{\text {dis }}$ is the contribution to the Gibbs energy based on composition expressed by the disordered solution phases formulae (independent of the ordering state of the phase), and $\Delta \mathrm{G}_{\mathrm{m}}^{\text {ord }}$ is the additional Gibbs energy due to ordering, i.e., configuration (contribution due to the long-range ordering, and must be zero in the when the phase is disordered):

$$
\Delta \mathrm{G}_{\mathrm{m}}^{\mathrm{ord}}=\mathrm{G}_{\mathrm{m}}^{\mathrm{ord}}\left(\mathrm{y}_{\mathrm{i}}\right)-\mathrm{G}_{\mathrm{m}}^{\mathrm{ord}}\left(\mathrm{y}_{\mathrm{i}}=\mathrm{x}_{\mathrm{i}}\right)
$$

where $y_{i}$ is the mole fraction of i per sublattice, also denoted site fraction, and $x_{i}$ the mole fraction. The parameter describing the ordering, $G_{m}^{\text {ord }}$, is first calculated with the original site fractions, $y$, which describe the ordering. The site fractions are then set equal to the mole fraction, $\mathrm{x}$, which means that each constituent has the same site fraction in all sublattices (i.e., disordered states), and the value of the expression is calculated again. The difference is the contribution to the Gibbs energy due to ordering. 
If the phase was originally disordered, the two terms are equal and the difference is zero (no driving for ordering).

The excess Gibbs energy term from Equation (2) is modeled using the Redlich-Kister [10] formalism for binary solutions and applied to multi-component systems via the Muggianu extrapolation [11], within the assumption that possible higher-order many-body interaction parameters can be ignored (above binary interactions). The resulting excess Gibbs energy term for a higher order system is written as:

$$
{ }^{e x} G_{m}^{\phi}=\sum_{i} \sum_{j>i} c_{i} c_{j} \sum_{v=0}^{p}{ }^{v} L_{i, j}^{\phi}\left(c_{i}-c_{j}\right)^{v}
$$

The Redlich-Kister model parameters, ${ }^{v} \mathrm{~L}_{\mathrm{i}, \mathrm{j}}^{\phi}$, describe the deviation from ideality and are chosen such that they satisfactorily represent all the available thermochemical and phase diagram data of the corresponding binaries. Generally, ${ }^{\mathrm{v}} \mathrm{L}_{\mathrm{i}, \mathrm{j}}^{\phi}$ is expressed as:

$$
{ }^{\mathrm{v}} \mathrm{L}_{\mathrm{i}, \mathrm{j}}^{\phi}=\mathrm{a}+\mathrm{bT}
$$

The excess Gibbs energy can also include, when necessary, ternary interaction parameters (e.g., $\mathrm{L}_{\mathrm{Fe}, \mathrm{Pu}, \mathrm{U}}^{\phi}$ for a multicomponent system. For $n$ elements:

$$
{ }^{e x, t e r n} G_{m}^{\phi}=\sum_{i=1}^{n-2} \sum_{j=i+1}^{n-1} \sum_{k=j+1}^{n} x_{i} x_{j} x_{k} L_{i, j, k}^{\phi}
$$

where:

$$
L_{i, j, k}^{\phi}=v_{i}^{i} L_{i, j, k}^{\phi}+v_{j}^{j} L_{i, j, k}^{\phi}+v_{k}{ }^{k} L_{i, j, k}^{\phi}
$$

with:

$$
\begin{aligned}
& \mathrm{v}_{\mathrm{i}}=\mathrm{x}_{\mathrm{i}}+\frac{1-\mathrm{x}_{\mathrm{i}}-\mathrm{x}_{\mathrm{j}}-\mathrm{x}_{\mathrm{k}}}{3} \\
& \mathrm{v}_{\mathrm{j}}=\mathrm{x}_{\mathrm{j}}+\frac{1-\mathrm{x}_{\mathrm{i}}-\mathrm{x}_{\mathrm{j}}-\mathrm{x}_{\mathrm{k}}}{3} \\
& \mathrm{v}_{\mathrm{k}}=\mathrm{x}_{\mathrm{k}}+\frac{1-\mathrm{x}_{\mathrm{i}}-\mathrm{x}_{\mathrm{j}}-\mathrm{x}_{\mathrm{k}}}{3}
\end{aligned}
$$

In the case of a ternary system (e.g., Fe-Pu-U) where $x_{i}+x_{j}+x_{k}=1$, (Equation (8)) reduces to:

$$
\mathrm{L}_{\mathrm{Fe}, \mathrm{Pu}, \mathrm{U}}^{\phi}=\mathrm{x}_{\mathrm{Fe}}{ }^{\mathrm{Fe}} \mathrm{L}_{\mathrm{Fe}, \mathrm{Pu}, \mathrm{U}}^{\phi}+\mathrm{x}_{\mathrm{Pu}}{ }^{\mathrm{Pu}} \mathrm{L}_{\mathrm{Fe}, \mathrm{Pu}, \mathrm{U}}^{\phi}+\mathrm{x}_{\mathrm{U}} \mathrm{U}_{\mathrm{Fe}, \mathrm{Pu}, \mathrm{U}}^{\phi}
$$

with:

$$
{ }^{\mathrm{i}} \mathrm{L}_{\mathrm{Fe}, \mathrm{Pu}, \mathrm{U}}^{\phi}=\mathrm{a}+\mathrm{bT}
$$

Stoichiometric binary and ternary compounds are described by the following function, where $x_{i}$ is the mole fraction of element $i$ in the phase/compound $\phi$ :

$$
\mathrm{G}_{\text {comp }}^{\phi}=\mathrm{a}+\mathrm{bT}+\sum_{\mathrm{i}} \mathrm{x}_{\mathrm{i}}^{0} \mathrm{G}_{\mathrm{i}}^{\Phi}
$$

In this case, $\mathrm{a}$ and $\mathrm{b}$ are the adjustable parameters used to model the Gibbs energy of binary or ternary stoichiometric compounds.

\subsection{Electronic Structure Calculations}

The results from all electronic-structure calculations come from applying density-functional theory (DFT) that took shape in the seminal papers by Hohenberg, Kohn, and Sham [12,13]. This theory is in 
principle exact, but it relies on a fundamental approximation, namely, the so-called electron exchange and correlation functional. For actinides as well as iron [14] the generalized gradient approximation (GGA) is currently the best approximation and is applied here. Specifically, the assumption for all DFT calculations is GGA either in its original form (PW91) [15] or the similar but simplified; Perdew, Burke and Ernzerhof (PBE) functional form [16].

Before detailing the electronic-structure methods used here, it is necessary to mention that theories which go beyond DFT have been applied to $5 f$-electron systems including uranium and plutonium metals. Savrasov and Kotliar [17] applied intra-atomic Coulomb correlations with a large Hubbard $\mathrm{U}$ of the order of $4-4.5 \mathrm{eV}$ in their DFT $+\mathrm{U}$ approach for plutonium and many other works using similar U (see references in [18]). Also, for uranium metal DFT $+\mathrm{U}$ has been applied [19] but it has been shown that with carefully executed DFT calculations this empirical parameter is not required for metallic uranium or plutonium (or alloys with iron) $[18,20]$.

For the plutonium system it is required for good accuracy to extend the DFT to include orbital-orbital coupling. This can be done rather straightforwardly by adopting the orbital-polarization scheme [18]. The orbital-orbital interaction enhances the magnitude of the orbital magnetic moment (caused by the spin-orbit interaction) and results in more realistic magnetic and chemical bonding properties. Here all-electron full-potential linear muffin-tin orbital (FPLMTO) calculations include spin-orbit coupling and orbital polarization. The orbital polarization tends to increase the stability of the respective compound relative to the spin-orbit only case.

In terms of the technical details of the calculations, for the most part, the FPLMTO method is applied, which has been described in detail [21]. In this method, no approximations are made for the electron core states that lie deeper in energy than the valence states, unlike the so-called pseudopotential method. The present implementation does not make any assumptions beyond that of the electron exchange and correlation functional. Basis functions, electron densities, and potentials are calculated without any geometrical approximation and these are expanded in spherical harmonics inside non-overlapping (muffin-tin) spheres surrounding each atom and in Fourier series in the region between these muffin-tin spheres. The theory includes all relativistic corrections including spin-orbit coupling for $d$ and $f$ states but not for the $p$ states [18].

The actinide metals have been shown to be very well described with $6 s$ and $6 p$ semi-core states and $7 s, 7 p, 5 f$, and $6 d$ valence states [22] and this setup is replicated here.For the calculation of the formation enthalpy one calculates the energies for the $\mathrm{An}_{6} \mathrm{Fe}(\mathrm{An}=\mathrm{Pu}, \mathrm{U})$ compound and subtract the energies of the constituents in their ground-state phase ( $\alpha$-An and $\alpha$-Fe). Ideally, if computationally feasible, these structures need to be optimized (adjusted or relaxed) so that the calculations produce the lowest total energy of the phase. For the FPLMTO calculations this has been done by calculating numerical forces from small atomic displacements [23]. For $\mathrm{An}_{6} \mathrm{Fe}, \alpha-\mathrm{Pu}, \alpha-\mathrm{U}, \alpha-\mathrm{Fe}$, a total of 128, 54, 256 , and $2000 \mathrm{k}$ points are included, respectively in the electronic-structure calculations. Each energy eigenvalue is broadened with a Gaussian having a width of $20 \mathrm{mRy}$.

When calculating the formation enthalpy, it is important to know precisely what the crystal structure is. For the studied compounds they are known (Table 2), except for $\mathrm{Pu}_{6} \mathrm{Fe}$ where detailed experimental information is lacking. The prototype structure is the same as $\mathrm{U}_{6} \mathrm{Fe}$, but the exact crystallographic parameters are not known. Therefore, it is necessary to calculate these parameters, or the energy will be too high for the compound. Hence, we have relaxed the crystal structure (i.e., found the structural parameters that correspond to the lowest total energy) for $\mathrm{Pu}_{6} \mathrm{Fe}$. The obtained parameters are significantly different than those for $\mathrm{U}_{6} \mathrm{Fe}$. For completeness, structural relaxation is performed for all FPLMTO calculations, but we find that for $\mathrm{U}_{6} \mathrm{Fe}$ the optimized structure is very close to the experimentally reported one.

The calculations referred to as exact muffin-tin orbital method (EMTO), are performed using the Green's-function technique based on the improved screened Korringa-Kohn-Rostoker method, where the one-electron potential is represented by optimized overlapping muffin-tin (OOMT) potential spheres $[24,25]$. Inside the potential spheres the potential is spherically symmetric, and it is constant 
between the spheres. The radius of the potential spheres, the spherical potential inside these spheres, and the constant value in the interstitial region are determined by minimizing (i) the deviation between the exact and overlapping potentials, and (ii) the errors caused by the overlap between the spheres. Within the EMTO formalism, the one-electron states are calculated exactly for the OOMT potentials. As an output of the EMTO calculations, one can determine self-consistent Green's function of the system and the complete, non-spherically symmetric charge density. Finally, the total energy is calculated using the full charge-density technique [26]. The valence states are treated as the $7 s, 6 p$, $6 d$, and $5 f$ states for $\mathrm{U}$ and $\mathrm{Pu}$ and $4 s$ and $3 d$ states for Fe. The corresponding Kohn-Sham orbitals are expanded in terms of spdf exact muffin-tin orbitals, i.e., an orbital momentum cutoff is applied, where $1_{\max }=3$. The EMTO orbitals, in turn, consist of the spdf partial waves (solutions of the radial Schrödinger equation for the spherical OOMT potential wells) and the spdf screened spherical waves (solutions of the Helmholtz equation for the OOMT muffin-tin zero potential). The completeness of the muffin-tin basis was discussed in detail in Ref. [25] and it was shown that for metals crystallizing in close-packed lattices $1_{\max }=3$ (spdf orbitals) leads to the well converged charge density and total energy. For the electron exchange and correlation energy functional, GGA (PBE96) is considered [27]. Integration over the Brillouin zone is performed using $25 \times 25 \times 25 \mathrm{k}$-points grid generated according to the Monkhorst-Pack scheme [28]. The moments of the density of states, needed for the kinetic energy and valence charge density, are calculated by integrating the Green's function over a complex energy contour (with 1.9-2.4 Ry diameter) using a Gaussian integration technique with 40 points on a semi-circle enclosing the occupied states. When treating compositional disorder, the EMTO method is combined with the coherent potential approximation (CPA) [24]. For instance, the EMTO-CPA formalism has been successfully used to describe thermodynamic properties of the metallic nuclear fuels, including: U-Zr, U-Mo, Pu-Zr, Pu-Mo, Pu-U, Pu-Np, Pu-Am, U-Ti, U-Nb, Np-Mo, Pu-Mo, for fast breeder reactors [29-36].

Relaxing (or optimizing for lowest energy) the crystal structures are not currently feasible and for this reason all calculations applying the EMTO assumes the experimental structure. For $\mathrm{Pu}_{6} \mathrm{Fe}$ the experimental structure is not known in detail and in this case the parameters for $\mathrm{U}_{6} \mathrm{Fe}$ have also been applied for $\mathrm{Pu}_{6} \mathrm{Fe}$.

\section{Literature Review}

As the thermodynamic assessments and their applications to the Pu-U [1,37], Pu-Ga [1,38-41], U-Ga [5,6] and Pu-U-Ga [1,42] systems are already available in the literature, the present study will only focus on the remaining systems (i.e., Pu-Fe, U-Fe, Fe-Ga, Pu-U-Fe, Pu-Fe-Ga, and U-Fe-Ga).

\subsection{The Plutonium-Iron Phase Diagram}

The Pu-Fe system has been experimentally investigated by Konobeevsky [43], Avivi [44], Mardon [45] and Ofte [46] using thermal analysis, dilatometry, metallography, x-ray diffraction (XRD), microhardness and viscosity measurements. The full phase diagram was studied by [43] and [45] whereas the authors in [44] focused on the $\mathrm{PuFe}_{2}$-Fe region and [46] investigated the liquidus range on the Pu-rich side up to 13 at. \% Fe. Formation enthalpies of the intermetallic $\mathrm{PuFe}_{2}$ and $\mathrm{Pu}_{6} \mathrm{Fe}$ phases were measured/estimated by [47-49] and [49] respectively. Elemental plutonium exists in 6 allotropic phases, including: simple-monoclinic $(\alpha-\mathrm{Pu})$, body-centered monoclinic $(\beta-\mathrm{Pu})$, face-centered orthorhombic $(\gamma-\mathrm{Pu})$, face-centered cubic (fcc or $\delta-\mathrm{Pu})$, body-centered tetragonal $\left(\delta^{\prime}-\mathrm{Pu}\right)$ and the body-centered cubic (bcc or $\varepsilon$-Pu). The lower-temperature Pu-allotropes $(\alpha, \beta$ and $\gamma$ ) exhibit limited (negligible) solubility of iron [50], whereas the higher-temperature phases (except $\delta^{\prime}-\mathrm{Pu}$ ) were found to have between $0.6-1.5$ at. \% Fe and 2-2.5 at. \% Fe for $\delta$-Pu and $\varepsilon$-Pu respectively, with Mardon [45] predicting higher solubilities than Elliott [51]. An interesting attribute of the Pu-rich side of the phase diagram includes a catatectic reaction $\left(430^{\circ} \mathrm{C}\right)$ between $\varepsilon$-Pu and $\delta$-Pu; upon cooling of $\varepsilon-\mathrm{Pu}$, a reappearance of the liquid phase (partial melting) occurs and is in equilibrium with the $\delta$-Pu phase. The eutectic reaction: [Liquid $\leftrightarrow \mathrm{Pu}_{6} \mathrm{Fe}+\delta$-Pu] was found at 90 at. $\% \mathrm{Pu}$ by [45], whereas other authors located the eutectic around $89-89.5$ and 91.5 at. $\% \mathrm{Pu}$ by [44] and [46] respectively. $\mathrm{Pu}_{6} \mathrm{Fe}$ 
decomposes peritectically into $\mathrm{PuFe}_{2}$ and liquid phases at $430{ }^{\circ} \mathrm{C}$ according to [43] or $428^{\circ} \mathrm{C}$ according to [45]. Thermal analysis measurements of $\mathrm{Pu}_{6} \mathrm{Fe}$ by [52] indicate an onset melting temperature at $411.5^{\circ} \mathrm{C}$ with a melting enthalpy of $6.77 \mathrm{~kJ} / \mathrm{mol}$. The $\mathrm{PuFe}_{2}$ intermetallic compound consists of 3 distinct polymorphs, with transition temperatures of $771{ }^{\circ} \mathrm{C}$ and $1020^{\circ} \mathrm{C}$ for $\alpha-\mathrm{PuFe}_{2} \rightarrow \beta-\mathrm{PuFe}_{2}$ and $\beta-\mathrm{PuFe}_{2} \rightarrow \gamma-\mathrm{PuFe}_{2}$ respectively; the compound melts congruently at $1240^{\circ} \mathrm{C}$. A eutectic reaction [Liquid $\leftrightarrow \mathrm{PuFe}_{2}+\gamma$-Fe] was identified by [45] at 18 at. $\% \mathrm{Pu}$ and $1165^{\circ} \mathrm{C}$, while other studies $[43,44$ ] placed the same reaction at 19 at. $\% \mathrm{Pu}$ and $1180^{\circ} \mathrm{C}$ [43]. Elemental iron transforms from bcc $(\alpha-\mathrm{Fe})$ to fcc $(\gamma-\mathrm{Fe})$ at $912{ }^{\circ} \mathrm{C}$ and back to bcc $(\delta-\mathrm{Fe})$ at $1394{ }^{\circ} \mathrm{C}$ and melts at $1538^{\circ} \mathrm{C}$. Very low solubility of $\mathrm{Pu}$ is reported in $\alpha$-Fe, at less than 0.02 at. $\% \mathrm{Pu}$ [53] and a eutectoid reaction $\left[\gamma-\mathrm{Fe} \leftrightarrow \alpha-\mathrm{Fe}+\mathrm{Fe}_{2} \mathrm{Pu}\right]$ at $907^{\circ} \mathrm{C}$ is observed by [44]. Higher solubility of $\mathrm{Pu}$ in the fcc $(\gamma-\mathrm{Fe})$ phase was reported by [44] with an average of 0.7 at. $\% \mathrm{Pu}$. The peritectic transformation [ $\mathrm{L}+\delta$-Fe $\leftrightarrow \gamma$-Fe] is suggested by [54] due to the presumed lower solubility of $\mathrm{Pu}$ in the high temperature bcc $(\delta-\mathrm{Fe})$ phase. Based on these experimental investigations, a complete thermodynamic assessment of the Pu-Fe phase diagram has been reported by $[2,3]$. In these assessments, the Pu-rich side did not include the solubility of Fe in the $\delta$-Pu and $\varepsilon$-Pu, which are pertinent to this study. Additionally, the intermetallic compounds were modelled using the liquid phase as their reference state, which is not consistent with the most recent and generally accepted CALPHAD-formulation for the standard refence state.

\subsection{The Uranium-Iron Phase Diagram}

The U-Fe system has been the source of many experimental investigations, with many authors performing thermal analysis including [55-62], some of whom also used dilatometry, metallography [63], XRD, microprobe analysis and calorimetric measurements [64]. The authors of $[57,58,63]$ focused on the U-rich side of the phase diagram, where the solubility of iron in $\gamma-\mathrm{U}$ (bcc structure) was found to be 1.3 at. \% Fe on average by [55-57,63]. The other two phases of uranium have no solubility reported for the orthorhombic $(\alpha-U)$ phase and limited information for the tetragonal $(\beta-U)$ phase with solubility at 0.37 at. $\%$ Fe or less [58]. The allotropic phase transitions occur at $668{ }^{\circ} \mathrm{C}$ and $776{ }^{\circ} \mathrm{C}$ from $\alpha-\mathrm{U}$ to $\beta-\mathrm{U}$ and $\beta-\mathrm{U}$ to $\gamma-\mathrm{U}$, respectively. A eutectoid reaction is reported around 0.1 at. $\%$ Fe between $661{ }^{\circ} \mathrm{C}$ and $675^{\circ} \mathrm{C}$ for $\left[\beta-\mathrm{U} \leftrightarrow \alpha-\mathrm{U}+\mathrm{U}_{6} \mathrm{Fe}\right]$. A similar reaction was reported for $\left[\gamma-\mathrm{U} \leftrightarrow \beta-\mathrm{U}+\mathrm{U}_{6} \mathrm{Fe}\right]$ between 0.5 and 0.8 at. $\%$. Fe, with an average reported temperature of $762{ }^{\circ} \mathrm{C}[54,58,63]$. The compound $\mathrm{U}_{6} \mathrm{Fe}$ forms from a peritectic decomposition of: [Liquid $+\gamma-\mathrm{U} \leftrightarrow \mathrm{U}_{6} \mathrm{Fe}$ ] with authors reporting temperatures between $795^{\circ} \mathrm{C}$ and $829^{\circ} \mathrm{C}[55,56,59,60,64]$. The low melting eutectic of [Liquid $\leftrightarrow \mathrm{U}_{6} \mathrm{Fe}+\mathrm{UFe}_{2}$ ] occurs at $725^{\circ} \mathrm{C}$ at 66 at. \% U according to [60]. The compound $\mathrm{UFe}_{2}$ was found to melt congruently between $1228{ }^{\circ} \mathrm{C}$ and $1235^{\circ} \mathrm{C}[55,56,60,64]$ and includes a eutectic reaction [Liquid $\leftrightarrow \mathrm{UFe}_{2}+\gamma$-Fe] at $1080^{\circ} \mathrm{C}$ and 17 at. \% uranium. The solubility of $\mathrm{U}$ in $\alpha$-Fe and $\gamma$-Fe are limited according to [55,56], since the $\delta$-Fe phase is analogous to that of $\alpha-\mathrm{Fe}$, it is assumed that the solubility is negligible, although quantitative data is not available. The currently accepted model by Kurata [3] for the U-Fe phase diagram includes similar discrepancies as the Pu-Fe system; there is little to no Fe solubility considered within the U-phases and the intermetallic compounds are not consistent with the most recent and generally accepted CALPHAD-formulation for the standard refence state.

\subsection{The Iron-Gallium Phase Diagram}

The Fe-Ga system was largely investigated by [65-72] with various techniques including thermal analysis, dilatometry, XRD, light microscope and Mössbauer spectroscopy to cover the full composition range of the system and elucidate phase relations, especially the complex ordering of the iron-rich $\mathrm{BCC}$ (including $\mathrm{D0}_{3}$ ) phases. The liquidus and solidus curves were measured by [65], who deduced the general shape of the phase diagram, but did not take into account the above-mentioned ordering on the iron rich side. Elemental gallium melts at $30^{\circ} \mathrm{C}$ and does not exhibit any solubility of iron within its structure. Two Ga-rich phases were found to form peritectically; $\mathrm{FeGa}_{3}$ phase decomposes at $824{ }^{\circ} \mathrm{C}$ into the monoclinic $\mathrm{Fe}_{3} \mathrm{Ga}_{4}$ and liquid phases with a composition of 81.5 and 85 at. \% Ga, according to [72] and [65] respectively. The second peritectic reaction occurs at $906^{\circ} \mathrm{C}\left[\mathrm{L}+\alpha^{\prime}(\mathrm{B} 2) \leftrightarrow \mathrm{Fe}_{3} \mathrm{Ga}_{4}\right]$. Both phases were found to have a small composition ranges by [65], which was confirmed by [67] for the 
$\mathrm{Fe}_{3} \mathrm{Ga}_{4}$ phase, but not the $\mathrm{FeGa}_{3}[67,72]$. Additionally, Köster et al. [66,67] identified the $\mathrm{Fe}_{6} \mathrm{Ga}_{5}$ phase, which was not considered by [65], that forms via a peritectoid reaction $\left[\alpha^{\prime}+\mathrm{Fe}_{3} \mathrm{Ga}_{4} \leftrightarrow \beta-\mathrm{Fe}_{6} \mathrm{Ga}_{5}\right]$ at $800{ }^{\circ} \mathrm{C}$ and exists in its $\alpha-\mathrm{Fe}_{6} \mathrm{Ga}_{5}$ polymorphic form below $778^{\circ} \mathrm{C}$. The $\mathrm{Fe}_{3} \mathrm{Ga}$ phase is found to be stable until $600{ }^{\circ} \mathrm{C}$ with a composition varying from $25-29$ at. \% Ga according to [65,71]. Köster et al. identified this phase as having two different polymorphs; the $\alpha-\mathrm{Fe}_{3} \mathrm{Ga}$ which exhibits a composition range between 26.1 and 29.5 at. \% Ga until 605 and $619^{\circ} \mathrm{C}$ respectively, above these temperatures the $\beta-\mathrm{Fe}_{3} \mathrm{Ga}$ phase is stable, with a slightly narrower composition range and transforms at $681{ }^{\circ} \mathrm{C}$ and 82.5 at. \% Fe into the $\alpha^{\prime \prime}$ (B2') phase. Gallium solubility in BCC iron extends to a maximum composition of 47.5 at. \% gallium and is accompanied by various ordered structures, including the $\alpha^{\prime}$ (B2) CsCl-type phase with composition range from 31.5 at. \% Ga up to the aforementioned maximum. The existence of this phase was verified by [68] and [71] via quenching from the liquid. Köster et al. [66] found that the $\alpha^{\prime}$ (B2) phase crystallizes directly from the melt at $1037^{\circ} \mathrm{C}$ and 35.5 at. $\% \mathrm{Ga}$, and the phase is stable down to $950^{\circ} \mathrm{C}$, below which the $\alpha^{\prime \prime}\left(\mathrm{B} 2^{\prime}\right)$ exists until $650{ }^{\circ} \mathrm{C}$ where it undergoes a eutectoid decomposition to $\alpha^{\prime \prime}\left(\mathrm{DO}_{3}\right)$ and $\alpha$-Fe (A2) and is coupled to the magnetic transition temperature of $\alpha$-Fe. Köster et al. [66,67] also identified an ordered phase $\alpha^{\prime \prime \prime}$ that is involved in a eutectoid reaction: $\left[\alpha^{\prime \prime \prime} \leftrightarrow \alpha-\mathrm{Fe}+\alpha-\mathrm{Fe}_{3} \mathrm{Ga}\right]$. The authors however were skeptical of the $\alpha^{\prime \prime \prime}$ phase being an equilibrium structure, since most of their samples in this phase region also contained traces of $\beta-\mathrm{Fe}_{3} \mathrm{Ga}$ and even found some samples containing two-phases: $\alpha-\mathrm{Fe}+\beta-\mathrm{Fe}_{3} \mathrm{Ga}$, making the latter structure the probable equilibrium phase. Köster et al. [66,67] indicated that the phase field between 21-26 at. \% Ga and $580-680^{\circ} \mathrm{C}$ is a likely metastable domain as reactions proceed extremely slowly and with difficulty in reproducing the data. Finally, there is limited solubility of gallium in $\gamma$-Fe (FCC), with a characteristic $\gamma$-loop in which the maximum solubility is 2.8 at. $\% \mathrm{Ga}$ at $1140{ }^{\circ} \mathrm{C}$.

\subsection{The Plutonium-Uranium-Iron Phase Diagram}

The Pu-U-Fe system was experimentally investigated by $[2,3,73-76]$. The first two papers consider a metallic fuel, either U-Pu-Zr [73] or U-Pu [74] with iron as a diffusion couple at $650{ }^{\circ} \mathrm{C}$ and $670{ }^{\circ} \mathrm{C}$ respectively. The experimental techniques include electroprobe microanalysis, EDX and SEM. It was found that the higher Pu containing fuels lead to increased liquid formation, since the liquid phase field extends into the $(\mathrm{Pu}, \mathrm{U})_{6} \mathrm{Fe}$ domain from the low-melting $\mathrm{Pu}_{6} \mathrm{Fe}$ compound. The solubility limits were found to be 16 at. $\% \mathrm{Pu}$ at $650{ }^{\circ} \mathrm{C}$ and estimated (based on models) to be 12 at. $\% \mathrm{Pu}$ at $670{ }^{\circ} \mathrm{C}$ in the $\mathrm{U}_{6} \mathrm{Fe}$ compound. Nakamura [75] and Kurata [2] prepared ternary Pu-U-Fe samples of varying composition by arc-melting, with [75] using DTA to elucidate ternary phase transitions from the prepared samples and [2] annealing the samples at $650{ }^{\circ} \mathrm{C}$ and characterizing them using XRD, SEM-EDS and chemical analysis. They were therefore able to establish a thermodynamic database derived from the information of these studies. This was later amended by Kurata et al. [3] to incorporate minor actinides within a CALPHAD database.

\subsection{The Plutonium-Iron-Gallium Phase Diagram}

No experimental data exists for this ternary system.

\subsection{The Uranium-Iron-Gallium Phase Diagram}

There have been six experimentally reported intermetallic compounds in the U-Fe-Ga phase space. They are UFeGa [77], $\mathrm{UFeGa}_{5}$, [78-81] $\mathrm{UFe}_{6} \mathrm{Ga}_{6}$ [82], $\mathrm{UFe}_{5} \mathrm{Ga}_{7}$ [83], $\mathrm{U}_{2} \mathrm{FeGa}_{8}$ [84] and $\mathrm{U}_{4} \mathrm{FeGa}_{12}$ [85]. The crystal structures of these phases have been investigated and low temperature experiments (up to $25^{\circ} \mathrm{C}$ ), including heat capacity, magnetic susceptibility and electrical resistivity have been performed [77-85]. There is no known information on phase stability above room temperature and a thermodynamic assessment with the given information is not possible.

\section{Crystal Structure}

The crystallographic information for the unary, binary and ternary systems described above are listed in Tables 1-3 respectively, the elemental crystal structures are also derived in the text. Information 
on structures related to the remaining binary systems are detailed in [1] for Pu-U, U-Ga and Pu-Ga. There are no specific compounds known for the ternary systems investigated.

Table 1. Crystal structure of unary systems.

\begin{tabular}{|c|c|c|c|c|c|c|}
\hline Phase & $\begin{array}{c}\text { Calphad } \\
\text { Designation }\end{array}$ & $\begin{array}{l}\text { Pearson } \\
\text { Symbol }\end{array}$ & $\begin{array}{l}\text { Space } \\
\text { Group }\end{array}$ & Strukturbericht & Prototype & $\begin{array}{l}\text { Transition } \\
\text { Temp. }\left({ }^{\circ} \mathrm{C}\right)\end{array}$ \\
\hline$\alpha-\mathrm{Fe}$ & BCC_A2 & $\mathrm{cF} 4$ & $\operatorname{Im} \overline{3} \mathrm{~m}$ & A2 & $\mathrm{W}$ & 912 \\
\hline$\gamma$-Fe & FCC_A1 & $\mathrm{cl} 2$ & $\mathrm{Fm} \overline{3} \mathrm{~m}$ & A1 & $\mathrm{Cu}$ & 1394 \\
\hline$\delta$-Fe & BCC_A2 & $\mathrm{cF} 4$ & $\operatorname{Im} \overline{3} \mathrm{~m}$ & $\mathrm{~A} 2$ & $\mathrm{~W}$ & 1538 \\
\hline$\alpha-\mathrm{Ga}$ & Orthorhombic_A11 & oC8 & Cmca & A11 & $\mathrm{Ga}$ & 30 \\
\hline$\alpha-\mathrm{Pu}$ & Alpha_Pu & $\mathrm{mP16}$ & $\mathrm{P} 22_{1} / \mathrm{m}$ & - & $\alpha-\mathrm{Pu}$ & 124 \\
\hline$\beta-\mathrm{Pu}$ & Beta_Pu & $\mathrm{mC} 34$ & $\mathrm{C}_{2} / \mathrm{m}$ & - & $\beta-\mathrm{Pu}$ & 215 \\
\hline$\gamma-\mathrm{Pu}$ & Gamma_Pu & $\mathrm{o} F 8$ & Fddd & - & $\gamma-\mathrm{Pu}$ & 320 \\
\hline$\delta-\mathrm{Pu}$ & FCC_A1 & $\mathrm{cF} 4$ & $\mathrm{Fm} \overline{3} \mathrm{~m}$ & A1 & $\mathrm{Cu}$ & 463 \\
\hline$\delta-\mathrm{Pu}$ & Tetragonal_A6 & $\mathrm{t} I 2$ & $\mathrm{I} 4 / \mathrm{mmm}$ & A6 & In & 483 \\
\hline$\varepsilon-\mathrm{Pu}$ & BCC_A2 & $\mathrm{cl} 2$ & $\operatorname{Im} \overline{3} \mathrm{~m}$ & A2 & $\mathrm{W}$ & 640 \\
\hline$\alpha-U$ & Orthorhombic_A20 & $\mathrm{oC4}$ & $\mathrm{Cmcm}$ & A20 & $\alpha-U$ & 668 \\
\hline$\beta-U$ & Tetragonal_U & $\mathrm{t} P 30$ & $\mathrm{P} 42 / \mathrm{mmm}$ & $A_{b}$ & $\beta-U$ & 776 \\
\hline$\gamma-\mathrm{U}$ & BCC_A2 & $\mathrm{cl} 2$ & $\operatorname{Im} \overline{3} \mathrm{~m}$ & $\mathrm{~A} 2$ & $\mathrm{~W}$ & 1135 \\
\hline
\end{tabular}

Table 2. Crystal structure of binary systems.

\begin{tabular}{|c|c|c|c|c|c|c|}
\hline Compound & Composition & $\begin{array}{l}\text { Pearson } \\
\text { Symbol }\end{array}$ & $\begin{array}{l}\text { Space } \\
\text { Group }\end{array}$ & Strukturbericht & Prototype & Refs. \\
\hline$\alpha^{\prime}$ & $\mathrm{Fe}_{0.75} \mathrm{Ga}_{0.25}$ & $c P 2$ & $\operatorname{Pm} \overline{3} \mathrm{~m}$ & B2 & $\mathrm{CsCl}$ & {$[86]$} \\
\hline$\alpha^{\prime \prime}$ & $\mathrm{Fe}_{3} \mathrm{Ga}$ & $c F 16$ & $\mathrm{Fm} \overline{3} \mathrm{~m}$ & - & - & [65] \\
\hline$\alpha^{\prime \prime \prime}$ & $\mathrm{Fe}_{3} \mathrm{Ga}$ & $c F 16$ & $\mathrm{Fm} \overline{3} \mathrm{~m}$ & $\mathrm{DO}_{3}$ & $\mathrm{BiF}_{3}$ & [87] \\
\hline$\alpha-\mathrm{Fe}_{3} \mathrm{Ga}$ & $\mathrm{Fe}_{2.8} \mathrm{Ga}_{1.2}$ & $c P 4$ & $\operatorname{Pm} \overline{3} \mathrm{~m}$ & $\mathrm{~L}_{2}$ & $\mathrm{AuCu}_{3}$ & [88] \\
\hline$\beta-\mathrm{Fe}_{3} \mathrm{Ga}$ & $\mathrm{Fe}_{3} \mathrm{Ga}$ & $h P 8$ & $\mathrm{P}_{3} / \mathrm{mmc}$ & $\mathrm{D}_{19}$ & $\mathrm{Ni}_{3} \mathrm{Sn}$ & [87] \\
\hline$\alpha-\mathrm{Fe}_{6} \mathrm{Ga}_{5}$ & $\mathrm{Fe}_{6} \mathrm{Ga}_{5}$ & $m C 44$ & $\mathrm{C} 2 / \mathrm{m}$ & - & $\mathrm{Al}_{8} \mathrm{Cl}_{5}$ & [69] \\
\hline$\beta-\mathrm{Fe}_{6} \mathrm{Ga}_{5}$ & $\mathrm{Fe}_{6} \mathrm{Ga}_{5}$ & $h R 26$ & $\mathrm{R} \overline{3} \mathrm{~m}$ & - & - & \\
\hline $\mathrm{Fe}_{3} \mathrm{Ga}_{4}$ & $\mathrm{Fe}_{3} \mathrm{Ga}_{4}$ & $m C 42$ & $\mathrm{C} 2 / \mathrm{m}$ & - & - & [89] \\
\hline $\mathrm{FeGa}_{3}$ & $\mathrm{FeGa}_{3}$ & $t P 16$ & $\mathrm{P} \overline{4} \mathrm{n} 2$ & - & $\mathrm{CoGa}_{3}$ & [90] \\
\hline$\alpha-(\mathrm{Pu}, \mathrm{U}) \mathrm{Fe}_{2}$ & $\mathrm{PuFe}_{2} / \mathrm{UFe}_{2}$ & $c F 24$ & $\mathrm{Fd} \overline{3} \mathrm{~m}$ & $\mathrm{C} 15$ & $\mathrm{Cu}_{2} \mathrm{Mg}$ & {$[45,91]$} \\
\hline$\beta-\mathrm{PuFe}_{2}$ & $\mathrm{PuFe}_{2}$ & $h P 24$ & $\mathrm{P} 63 / \mathrm{mmc}$ & $\mathrm{C} 36$ & $\mathrm{MgNi}_{2}$ & [7] \\
\hline$\gamma-\mathrm{PuFe}_{2}$ & $\mathrm{PuFe}_{2}$ & $c^{* *}$ & & - & & [7] \\
\hline$(\mathrm{Pu}, \mathrm{U})_{6} \mathrm{Fe}$ & $\mathrm{Pu}_{6} \mathrm{Fe} / \mathrm{U}_{6} \mathrm{Fe}$ & $t / 28$ & $\mathrm{I} \overline{4} / \mathrm{mcm}$ & $\mathrm{D} 2_{\mathrm{c}}$ & $\mathrm{MnU}_{6}$ & {$[45,92]$} \\
\hline
\end{tabular}

Table 3. Crystal Structure of U-Fe-Ga intermetallic compounds.

\begin{tabular}{cccccc}
\hline Compound & Pearson Symbol & Space Group & Strukturbericht & Prototype & Refs. \\
\hline $\mathbf{U F e G a}$ & $h P 9$ & $\mathrm{P} 62 \mathrm{~m}$ & $\mathrm{C} 22$ & $\mathrm{Fe}_{2} \mathrm{P}$ & {$[77]$} \\
$\mathbf{U F e G a}$ & $t P 7$ & $\mathrm{P} 4 / \mathrm{mmm}$ & - & $\mathrm{HoCoGa}_{5}$ & {$[78,81]$} \\
$\mathbf{U F e}_{\mathbf{6}} \mathrm{Ga}_{\mathbf{6}}$ & $t I 26$ & $\mathrm{I} / \mathrm{mmm}$ & $\mathrm{D} 2_{\mathrm{b}}$ & $\mathrm{ThMn}_{12}$ & {$[82]$} \\
$\mathbf{U F e}_{5} \mathrm{Ga}_{7}$ & $t I 26$ & $\mathrm{I} / \mathrm{mmm}$ & $\mathrm{D} 2_{\mathrm{b}}$ & $\mathrm{ThMn}_{12}$ & {$[83]$} \\
$\mathbf{U}_{\mathbf{2}} \mathrm{FeGa}_{8}$ & $t P 11$ & $\mathrm{P} 4 / \mathrm{mmm}$ & - & $\mathrm{Ho}_{2} \mathrm{CoGa}_{8}$ & {$[84]$} \\
$\mathbf{U}_{\mathbf{4}} \mathrm{FeGa}_{\mathbf{1 2}}$ & $c I 34$ & $\mathrm{Im} \overline{3} \mathrm{~m}$ & - & $\mathrm{Y}_{4} \mathrm{PdGa}_{12}$ & {$[85]$} \\
\hline
\end{tabular}

\section{Results and Discussion}

The re-assessed parameters for the Pu-Fe, U-Fe and Pu-U-Fe system are listed in Table 4 along with the newly assessed Fe-Ga parameters. Since no thermodynamic information is available on the $\mathrm{Pu}-\mathrm{Fe}-\mathrm{Ga}$ and $\mathrm{U}-\mathrm{Fe}-\mathrm{Ga}$ ternary systems, the extrapolation from binary parameters were deemed sufficient. Table 5 compares the invariant reactions for each of the binaries with experiment and available models in the literature, Table 6 compares the formation enthalpies found in experimental and theoretical literature to the values calculated from the electronic structure methods described in this work and those obtained with the newly assessed CALPHAD model. 
Table 4. Parameters for Pu-Fe, U-Fe, Pu-U-Fe and Fe-Ga systems.

\begin{tabular}{|c|c|c|c|}
\hline Phase & Parameter & Kurata $[2,3] * *$ & This Work \\
\hline \multirow[t]{12}{*}{ Liquid } & ${ }^{0} \mathrm{~L}_{\mathrm{Fe}, \mathrm{Pu}}$ & $-35,332+27.530 \times \mathrm{T}$ & $-23,000+2.1 \times \mathrm{T}$ \\
\hline & ${ }^{1} \mathrm{~L}_{\mathrm{Fe}, \mathrm{Pu}}$ & -8149.0 & 380 \\
\hline & ${ }^{2} \mathrm{~L}_{\mathrm{Fe}, \mathrm{Pu}}$ & -4933.0 & 2680 \\
\hline & ${ }^{0} \mathrm{~L}_{\mathrm{Fe}, \mathrm{U}}$ & $-46,128-0.13459 \times \mathrm{T}$ & $-30,613.93-22.81 \times \mathrm{T}$ \\
\hline & ${ }^{1} \mathrm{~L}_{\mathrm{Fe}, \mathrm{U}}$ & $-11,776$ & $-57,241.80+41.34 \times \mathrm{T}$ \\
\hline & ${ }^{2} \mathrm{~L}_{\mathrm{Fe}, \mathrm{U}}$ & 9258.5 & $-1988.06+7.3308 \times \mathrm{T}$ \\
\hline & ${ }^{0} \mathrm{~L}_{\mathrm{Fe}, \mathrm{Pu}, \mathrm{U}}$ & $10,000 * *$ & $-14,000$ \\
\hline & ${ }^{1} \mathrm{~L}_{\mathrm{Fe}, \mathrm{Pu}, \mathrm{U}}$ & N/A & -9500 \\
\hline & ${ }^{2} \mathrm{~L}_{\mathrm{Fe}, \mathrm{Pu}, \mathrm{U}}$ & N/A & $-10,000$ \\
\hline & ${ }^{0} \mathrm{~L}_{\mathrm{Fe}, \mathrm{Ga}}$ & N/A & $-86,500+18 \times \mathrm{T}$ \\
\hline & ${ }^{1} \mathrm{~L}_{\mathrm{Fe}, \mathrm{Ga}}$ & N/A & $-15,363+3.5 \times \mathrm{T}$ \\
\hline & ${ }^{2} \mathrm{~L}_{\mathrm{Fe}, \mathrm{Ga}}$ & N/A & $-13,000$ \\
\hline \multirow[t]{6}{*}{ BCC $(\varepsilon-\mathbf{P u}, \gamma-\mathbf{U})$} & ${ }^{0} \mathrm{~L}_{\mathrm{Fe}, \mathrm{Pu}}$ & 13,000 & 7295 \\
\hline & ${ }^{1} \mathrm{~L}_{\mathrm{Fe}, \mathrm{Pu}}$ & 8500 & 12,150 \\
\hline & ${ }^{0} \mathrm{~L}_{\mathrm{Fe}, \mathrm{U}}$ & 1204.5 & 53,000 \\
\hline & ${ }^{1} \mathrm{~L}_{\mathrm{Fe}, \mathrm{U}}$ & 0 & 66,000 \\
\hline & ${ }^{0} \mathrm{~L}_{\mathrm{Fe}, \mathrm{Ga}}$ & N/A & $-104,669+26.3 \times \mathrm{T}$ \\
\hline & ${ }^{1} \mathrm{~L}_{\mathrm{Fe}, \mathrm{Ga}}$ & N/A & $8000-19 \times \mathrm{T}$ \\
\hline \multirow[t]{5}{*}{ FCC $(\delta-\mathrm{Pu}, \gamma-\mathrm{Fe})$} & ${ }^{0} \mathrm{~L}_{\mathrm{Fe}, \mathrm{Pu}}$ & 18,000 & 11,250 \\
\hline & ${ }^{1} \mathrm{~L}_{\mathrm{Fe}, \mathrm{Pu}}$ & 3000 & 7250 \\
\hline & ${ }^{0} \mathrm{~L}_{\mathrm{Fe}, \mathrm{U}}$ & -3595.3 & $18,142.90$ \\
\hline & ${ }^{0} \mathrm{~L}_{\mathrm{Fe}, \mathrm{Ga}}$ & N/A & $-107,800+28 \times T$ \\
\hline & ${ }^{1} \mathrm{~L}_{\mathrm{Fe}, \mathrm{Ga}}$ & N/A & $19,800-24 \times \mathrm{T}$ \\
\hline $\begin{array}{c}\text { TETRAGONAL_U } \\
(\beta-\mathrm{U})\end{array}$ & ${ }^{0} \mathrm{~L}_{\mathrm{Fe}, \mathrm{U}}$ & 30,000 & -8400 \\
\hline \multirow[t]{2}{*}{$(\mathrm{Pu}, \mathrm{U}) \mathrm{Fe}_{2}$} & $\begin{array}{c}\mathrm{G}_{\mathrm{Fe}: P u} \\
\mathrm{G}_{\mathrm{Fe}: U}\end{array}$ & $\begin{array}{l}-61902+26.18 \times \mathrm{T}+\text { GPULIQ }+2 \times \text { GFELIQ } \\
-106,537+33.251+\text { GULIQ }+2 \times \text { GFELIQ }\end{array}$ & $\begin{array}{c}-15850+0.53 \times \mathrm{T}+0.333 \times \text { GHSERPU }+0.667 \times \text { GHSERFE } \\
-21,061.115-0.281944 \times \mathrm{T}+0.333 \times \text { GHSERUU }+0.667 \times \text { GHSERFE }\end{array}$ \\
\hline & ${ }^{0} \mathrm{~L}_{\mathrm{Fe}: \mathrm{Pu}, \mathrm{U}}$ & 0 & -5000 \\
\hline \multirow[t]{3}{*}{$(\mathrm{Pu}, \mathrm{U})_{6} \mathrm{Fe}$} & $\mathrm{G}_{\mathrm{Fe}: \mathrm{Pu}}$ & $-91,210$ + 90.6 × T + 6× GPULIQ + GLIQFE & $-17,850-31.2 \times \mathrm{T}+6 \times$ GHSERPU + GHSERFE \\
\hline & $\mathrm{G}_{\mathrm{Fe}: U}$ & $-149,660+88.270 \times \mathrm{T}+6 \times$ GPULIQ + GLIQFE & $-49,520.86-3.709854 \times \mathrm{T}+6 \times$ GHSERUU + GHSERFE \\
\hline & $\mathrm{L}_{\mathrm{Fe}: \mathrm{Pu}, \mathrm{U}}$ & 0 & 4500 \\
\hline $\mathrm{Fe}_{3} \mathrm{Ga}$ & $\mathrm{G}_{\mathrm{Fe}: \mathrm{Ga}}$ & N/A & $-25,875+3.7 \times \mathrm{T}+0.75 \times$ GHSERFE $+0.25 \times$ GHSERGA \\
\hline $\mathrm{Fe}_{6} \mathrm{Ga}_{5}$ & $\mathrm{G}_{\mathrm{Fe}: \mathrm{Ga}}$ & N/A & $-32,594+3.3 \times \mathrm{T}+0.546 \times$ GHSERFE $+0.454 \times$ GHSERGA \\
\hline $\mathrm{Fe}_{3} \mathrm{Ga}_{4}$ & $\mathrm{G}_{\mathrm{Fe}: \mathrm{Ga}}$ & N/A & $-33,545+3.0 \times \mathrm{T}+0.429 \times$ GHSERFE $+0.571 \times$ GHSERGA \\
\hline $\mathrm{FeGa}_{3}$ & $\mathrm{G}_{\mathrm{Fe}: \mathrm{Ga}}$ & N/A & $-27,275+0.1 \times \mathrm{T}+0.25 \times$ GHSERFE $+0.75 \times$ GHSERGA \\
\hline
\end{tabular}




\subsection{Pu-Fe Assessment}

The assessment of the Pu-Fe phase diagram was performed across the full composition and temperature ranges. The calculated phase diagram for the Pu-Fe system is indicated in Figure 1 and compared to available experimental data from Mardon [45] and Ofte [46].

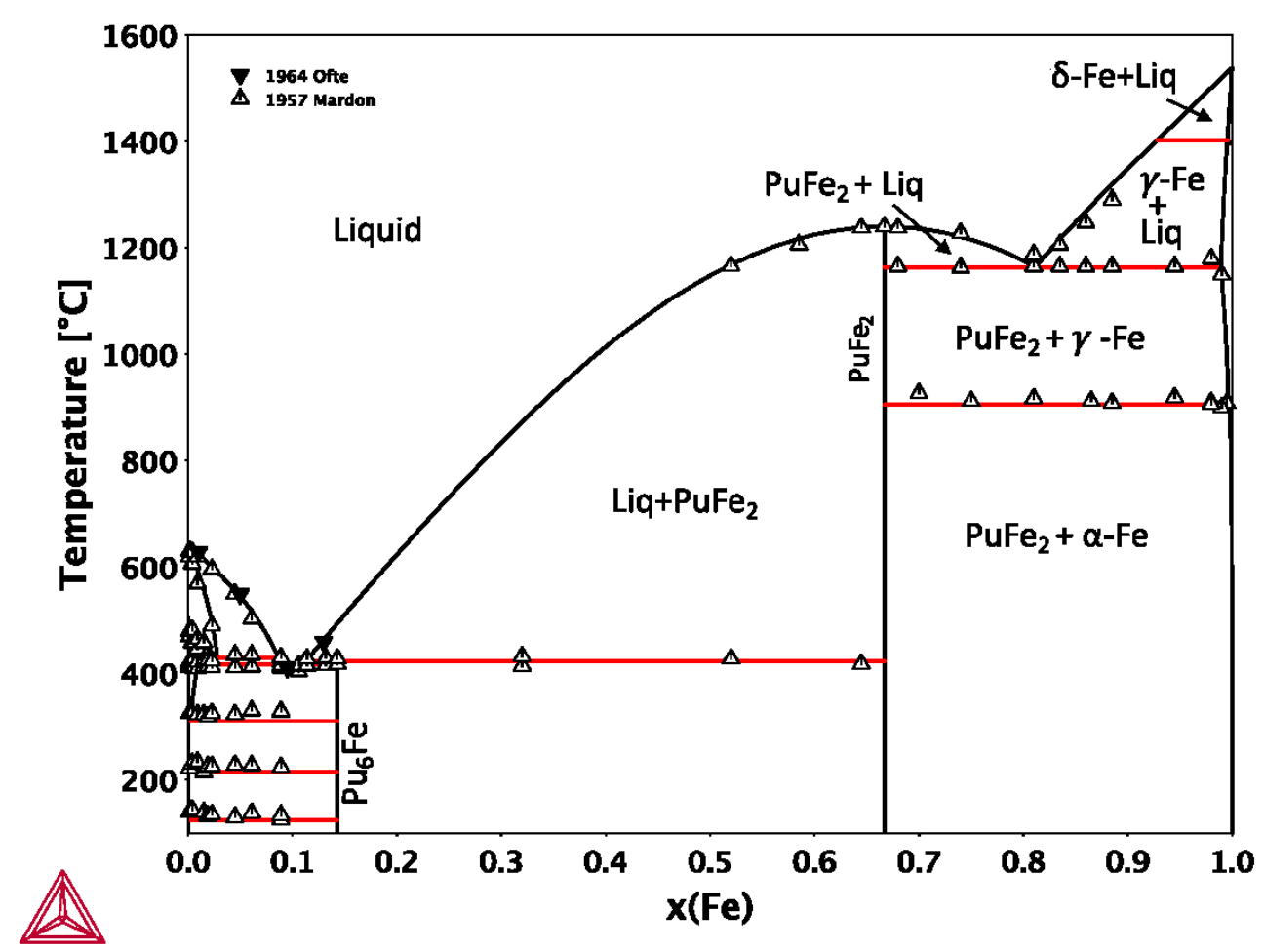

Figure 1. Calculated Pu-Fe phase diagram based on the present CALPHAD assessment and compared with experimental data $[45,46]$.

In Table 5, the current assessment is also compared to that of Kurata [3] and considerable improvements are to be noted. For the iron-rich side, the congruent melting temperature of the $\mathrm{PuFe}_{2}$ compound is improved and the higher solubility limit of $\mathrm{Pu}$ in $\gamma$-Fe is realized. Note that most of the amendments were made of the Pu-rich side (Figure 2), as that is the domain where iron-impurities are of interest. For the low-temperature allotropes $(\alpha, \beta$ and $\gamma)$ of plutonium, iron solubility was not considered as there is limited (or negligible) experimental evidence. An overall improved fit of the liquidus and solidus data on the Pu-rich side was achieved. Specifically, the solubility of iron in both $\delta-\mathrm{Pu}$ and $\varepsilon-\mathrm{Pu}$ were improved (from 0.4 at. \% to 0.9 at. \%, and 1.9 at. $\%$ to 2.7 at. \%, respectively) and in better agreement with literature (1.3 at. \% Fe and 2.4 at. \% Fe, respectively). The invariant reaction temperatures were also ameliorated across the phase diagram, compared to the previous assessment, especially in the $\mathrm{Pu}-\mathrm{Pu}_{6} \mathrm{Fe}$ phase domain. The stoichiometric compounds were re-assessed to include the generally used standard reference states $(\alpha-\mathrm{Pu}$ and $\alpha-\mathrm{Fe})$ compared to Kurata et al. [3], who used the liquid phase as their reference state. Table 6 indicates that the formation enthalpy of $\mathrm{PuFe}_{2}$ calculated from the thermodynamic database in this work is in good agreement with the solution calorimetry measurements of [49] but is much less stable than the experimental value reported in [48] using e.m.f. techniques and the EMTO calculations presented in this work. Initial attempts to use the EMTO calculated values to optimize the Pu-Fe system included a more stable formation enthalpy for $\mathrm{PuFe}_{2}$ were unsuccessful. 
Table 5. Invariant reactions for Fe-Ga, Pu-Fe and U-Fe systems compared with experiments and models.

\begin{tabular}{|c|c|c|c|c|c|c|}
\hline \multirow{2}{*}{$\begin{array}{c}\text { Reaction Type } \\
1 \text { Congruent }\end{array}$} & \multirow{2}{*}{$\begin{array}{c}\text { Reaction } \\
\alpha^{\prime \prime} \leftrightarrow \beta-\mathrm{Fe}_{3} \mathrm{Ga}\end{array}$} & \multicolumn{3}{|c|}{ Composition at. $\% \mathrm{Fe}$} & \multirow{2}{*}{$\frac{\text { Temp }\left({ }^{\circ} \mathrm{C} / \mathrm{K}\right)}{680 / 953}$} & \multirow{2}{*}{$\begin{array}{c}\text { Refs. } \\
{[65]}\end{array}$} \\
\hline & & 72.5 & 72.5 & 72.5 & & \\
\hline & & 75 & 75 & 75 & $703 / 976$ & This work \\
\hline \multirow{2}{*}{2 Peritectic } & $\mathrm{L}+\alpha^{\prime} \leftrightarrow \mathrm{Fe}_{3} \mathrm{Ga}_{4}$ & 38.2 & $52 / 52.5$ & 43 & $906 / 1173$ & [64-66] \\
\hline & & 39.7 & 49.3 & 42.9 & $911 / 1178$ & This work \\
\hline 3 Peritectic & $\mathrm{L}+\mathrm{Fe}_{3} \mathrm{Ga}_{4} \leftrightarrow \mathrm{FeGa}_{3}$ & 18.5 & 42 & 25 & $824 / 1097$ & {$[65,66]$} \\
\hline Eutectic & & 28.4 & 42.9 & 25 & $825 / 1097$ & This work \\
\hline \multirow{2}{*}{4 Peritectic } & $\mathrm{L}+\mathrm{Fe}_{3} \mathrm{Ga}_{4} \leftrightarrow \alpha-\mathrm{Ga}$ & 0.1 & 25 & - & $34 / 307$ & {$[65,66]$} \\
\hline & & 0.1 & 25 & - & $34 / 303$ & This work \\
\hline \multirow[t]{2}{*}{5 Peritectoid } & $\alpha^{\prime}+\mathrm{Fe}_{3} \mathrm{Ga}_{4} \leftrightarrow \beta-\mathrm{Fe}_{6} \mathrm{Ga}_{5}$ & 58 & 43.5 & 55 & $800 / 1073$ & {$[65,66]$} \\
\hline & & 54.7 & 42.9 & 54.6 & $800 / 1073$ & This work \\
\hline \multirow[t]{2}{*}{6 Peritectoid } & $\beta-\mathrm{Fe}_{6} \mathrm{Ga}_{5}+\mathrm{Fe}_{3} \mathrm{Ga}_{4} \leftrightarrow \alpha-\mathrm{Fe}_{6} \mathrm{Ga}_{5}$ & 54.5 & 43.5 & 54.5 & $778 / 1051$ & {$[65,66]$} \\
\hline & & - & - & - & - & This work \\
\hline \multirow[t]{2}{*}{7 Peritectoid } & $\beta-\mathrm{Fe}_{3} \mathrm{Ga}_{4}+\mathrm{Fe}_{6} \mathrm{Ga}_{5} \leftrightarrow \alpha-\mathrm{Fe}_{3} \mathrm{Ga}$ & 71 & 56.5 & 70.8 & $619 / 892$ & {$[65,66]$} \\
\hline & & - & - & - & - & This work \\
\hline \multirow[t]{2}{*}{8 Eutectoid } & $\beta-\mathrm{Fe}_{6} \mathrm{Ga}_{5} \leftrightarrow \alpha^{\prime}+\alpha-\mathrm{Fe}_{6} \mathrm{Ga}_{5}$ & 55.5 & 59 & 55.5 & $770 / 1043$ & {$[65,66]$} \\
\hline & & - & - & - & - & This work \\
\hline \multirow[t]{2}{*}{9 Eutectoid } & $\alpha^{\prime} \leftrightarrow \beta-\mathrm{Fe}_{3} \mathrm{Ga}+\mathrm{Fe}_{6} \mathrm{Ga}_{5}$ & 66.5 & 71 & 56.5 & $625 / 898$ & {$[65,66]$} \\
\hline & & 67.1 & 75 & 56.5 & $605 / 883$ & This work \\
\hline 10 Eutectoid & $\beta-\mathrm{Fe}_{3} \mathrm{Ga} \leftrightarrow \alpha^{\prime \prime}+\alpha-\mathrm{Fe}_{3} \mathrm{Ga}$ & 74 & 75 & 73.8 & $605 / 878$ & {$[65,66]$} \\
\hline & & - & - & - & - & This work \\
\hline 11 Eutectoid & $\alpha^{\prime \prime \prime} \leftrightarrow \alpha-\mathrm{Fe}+\alpha-\mathrm{Fe}_{3} \mathrm{Ga}$ & 76.6 & 79.4 & 73.7 & $588 / 861$ & {$[65,66]$} \\
\hline & & - & - & - & - & This work \\
\hline 12 Congruent & $\mathrm{L} \leftrightarrow \mathrm{PuFe}_{2}$ & 66.67 & 66.67 & 66.67 & $1240 / 1513$ & [45] \\
\hline & & 66.67 & 66.67 & 66.67 & $1240 / 1513$ & This work \\
\hline & & 66.67 & 66.67 & 66.67 & $1258 / 1531$ & [3] \\
\hline 13 Peritectic & $\mathrm{L}+\mathrm{PuFe}_{2} \leftrightarrow \mathrm{Pu}_{6} \mathrm{Fe}$ & 11.5 & 66.67 & 14.29 & $428 / 701$ & [45] \\
\hline & & 11.3 & 66.67 & 14.29 & $423.5 / 696.5$ & This work \\
\hline & & 13.7 & 66.67 & 14.29 & $429.2 / 702.2$ & [3] \\
\hline 14 Catatectic & $\mathrm{L}+\delta-\mathrm{Fe} \leftrightarrow \gamma-\mathrm{Fe}$ & 94 & 98.8 & 100 & $1400 / 1673$ & [44] \\
\hline & & 92.9 & 99.6 & 100 & $1402 / 1675$ & This work \\
\hline & & 92.9 & 98.6 & 100 & $1404 / 1677$ & [3] \\
\hline 15 Catatectic & $\mathrm{L}+\delta-\mathrm{Pu} \leftrightarrow \varepsilon-\mathrm{Pu}$ & 8.5 & 1.3 & 2.4 & $430 / 703$ & [45] \\
\hline & & 8.7 & 0.9 & 2.7 & $429.5 / 702.5$ & This work \\
\hline & & 7.6 & 0.4 & 1.9 & $444.5 / 716.5$ & [3] \\
\hline 16 Eutectoid & $\gamma-\mathrm{Fe} \leftrightarrow \alpha-\mathrm{Fe}+\mathrm{PuFe}_{2}$ & 99 & 100 & 66.67 & $907 / 1180$ & [46] \\
\hline & & 99.7 & 100 & 66.67 & $905 / 1178$ & This work \\
\hline & & 98.9 & 100 & 66.67 & $894 / 1166$ & [3] \\
\hline 17 Eutectic & $\mathrm{L} \leftrightarrow \gamma-\mathrm{Fe}+\mathrm{PuFe}_{2}$ & 82 & 98.8 & 66.7 & $1165 / 1438$ & [45] \\
\hline & & 81.2 & 98.9 & 66.7 & $1164 / 1437$ & This work \\
\hline & & 81.2 & 97 & 66.7 & $1135 / 1408$ & [3] \\
\hline 18 Eutectic & $\mathrm{L} \leftrightarrow \delta-\mathrm{Pu}+\mathrm{Pu}_{6} \mathrm{Fe}$ & 9.5 & 0.5 & 14.29 & $413 / 686$ & [46] \\
\hline & & 9.35 & 0.9 & 14.29 & $416.6 / 689.6$ & This work \\
\hline & & 8.9 & 0.4 & 14.29 & $420 / 693$ & [3] \\
\hline 19 Congruent & $\mathrm{L} \leftrightarrow \mathrm{UFe}_{2}$ & 66.67 & 66.67 & 66.67 & $1230 / 1503$ & [55] \\
\hline & & 66.67 & 66.67 & 66.67 & $1230 / 1503$ & This work \\
\hline & & 66.67 & 66.67 & 66.67 & $1236 / 1509$ & [4] \\
\hline & & 66.67 & 66.67 & 66.67 & $1227 / 1500$ & [3] \\
\hline 20 Peritectic & $\mathrm{L}+\gamma-\mathrm{U} \leftrightarrow \mathrm{U}_{6} \mathrm{Fe}$ & 15 & 1.5 & 14.39 & $832 / 1102$ & [64] \\
\hline & & 15.25 & 1.32 & 14.29 & $832 / 1102$ & This work \\
\hline & & 15.06 & 1.35 & 14.29 & $834 / 1104$ & [4] \\
\hline & & 19.09 & 1.14 & 14.29 & 1075.5 & [3] \\
\hline 21 Eutectoid & $\gamma-\mathrm{U} \leftrightarrow \beta-\mathrm{U}+\mathrm{U}_{6} \mathrm{Fe}$ & 0.8 & 0.37 & 14.29 & $762 / 1035$ & {$[60]$} \\
\hline & & 0.85 & 0.37 & 14.29 & $764 / 1037$ & This work \\
\hline & & N/A & 0.46 & 14.29 & $766 / 1039$ & [4] \\
\hline & & 0.70 & 0 & 14.29 & $763 / 1036$ & [3] \\
\hline 22 Eutectoid & $\beta-\mathrm{U} \leftrightarrow \alpha-\mathrm{U}+\mathrm{U}_{6} \mathrm{Fe}$ & 0.175 & 0.05 & 14.29 & $669 / 942$ & {$[60]$} \\
\hline & & 0.172 & 0 & 14.29 & $664.4 / 937.4$ & This work \\
\hline & & 0.16 & 0 & 14.29 & $664.8 / 937.8$ & [4] \\
\hline 23 Eutectic & $\mathrm{L} \leftrightarrow \gamma-\mathrm{Fe}+\mathrm{UFe}_{2}$ & 83 & 0 & 66.67 & $1080 / 1353$ & {$[55,56,60]$} \\
\hline & & 82.7 & 0 & 66.67 & $1079 / 1352$ & This work \\
\hline & & 82.55 & 0 & 66.67 & $1078 / 1351$ & [4] \\
\hline & & 83 & 0 & 66.67 & $1080 / 1353$ & [3] \\
\hline 24 Eutectic & $\mathrm{L} \leftrightarrow \mathrm{UFe}_{2}+\mathrm{U}_{6} \mathrm{Fe}$ & 34 & 66.67 & 14.29 & $723 / 996$ & {$[60]$} \\
\hline & & 33.85 & 66.67 & 14.29 & $723.4 / 996.4$ & This work \\
\hline & & 33.49 & 66.67 & 14.29 & $719.4 / 992.5$ & [4] \\
\hline & & 31.16 & 66.67 & 14.29 & 725.1/998.1 & [3] \\
\hline
\end{tabular}


Table 6. $\Delta_{\mathrm{f}} \mathrm{H}(\mathrm{kJ} / \mathrm{mol})$ of Pu-Fe and U-Fe compounds compared to DFT calculations and experiment.

\begin{tabular}{ccccc}
\hline Method/Refs. & $\mathbf{P u}_{\mathbf{6}} \mathbf{F e}$ & $\mathbf{U}_{6} \mathbf{F e}$ & $\mathbf{P u F e}_{\mathbf{2}}$ & $\mathbf{U F e}_{\mathbf{2}}$ \\
\hline CALPHAD (This work) & -1.2 & -5.8 & -9.8 & -15 \\
Experiment & $\mathrm{N} / \mathrm{A}$ & $-6.8 /-7.3$ & $\mathrm{~N} / \mathrm{A}$ & $-16.3 /-15.8$ \\
[64]/CALPHAD [4] & -4.4 & -7.8 & -5.1 & -5.2 \\
CALPHAD [3] & $\mathrm{N} / \mathrm{A}$ & -2.33 & -13.1 & -11.30 \\
Experiment [47] & $\mathrm{N} / \mathrm{A}$ & $-2.33 \pm 0.72$ & $\mathrm{~N} / \mathrm{A}$ & -10.74 \\
Experiment [93] & $-1.97 \pm 0.65$ & $\mathrm{~N} / \mathrm{A}$ & $-9.06 \pm 0.56$ & $\mathrm{~N} / \mathrm{A}$ \\
Experiment [49] & $\mathrm{N} / \mathrm{A}$ & $\mathrm{N} / \mathrm{A}$ & -16.6 & N/A \\
Experiment [48] & -0.50 & -6.17 & -16.25 & -16.0 \\
SR-EMTO (This work) & 0 & -2.5 & -11.6 & -15.5 \\
FPLMTO (This work) & & & & \\
\hline
\end{tabular}

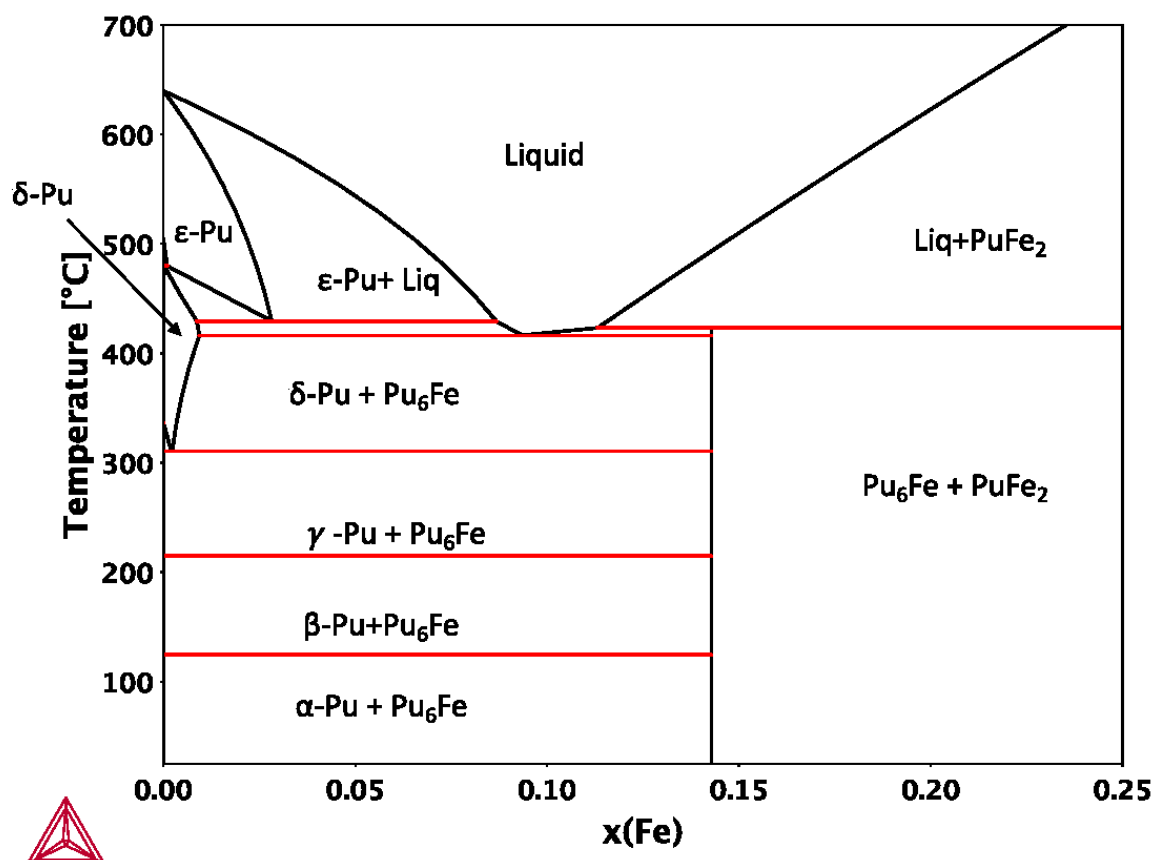

Figure 2. Calculated Pu-rich side of the $\mathrm{Pu}-\mathrm{Fe}$ phase diagram based on the present CALPHAD assessment.

Since the relaxed structure calculations using FPLMTO resulted in a less stable formation enthalpy, it is regarded as a more suitable starting point for fitting the $\mathrm{PuFe}_{2}$ intermetallic. In order to fit both liquidus data of [45] and include an accurate description of the $\mathrm{PuFe}_{2}$ compounds congruent melting, the formation enthalpy was lowered and found to be less stable than that of the EMTO calculations, the estimated values (based on the analogous $\mathrm{UFe}_{2}$ ) of [47] and the experimental work of [48]. The value for $\mathrm{Pu}_{6} \mathrm{Fe}$ calculated from CALPHAD lies in between that calculated via DFT and the experimentally available values, where the EMTO value (with an uncertainty of $1.3 \mathrm{~kJ} / \mathrm{mol}$ ) was used as a starting point for the parameters during optimization. The enthalpy of melting $(6.77 \mathrm{~kJ} / \mathrm{mol})$ derived by [52] at $411.5^{\circ} \mathrm{C}$ for the $\mathrm{Pu}_{6} \mathrm{Fe}$ compound agrees well with the peritectic decomposition temperature of $423.5^{\circ} \mathrm{C}$ and reaction enthalpy of $6.51 \mathrm{~kJ} / \mathrm{mol}$ calculated from this work.

\subsection{U-Fe Assessment}

The calculated phase diagram resulting from the present CALPHAD assessment is depicted in Figure 3. Overall improvements including the solubility of iron into the uranium lattice ( $\beta-\mathrm{U}$ and $\gamma-\mathrm{U})$ is provided and is indicated in the invariant reactions described in Table 5. 


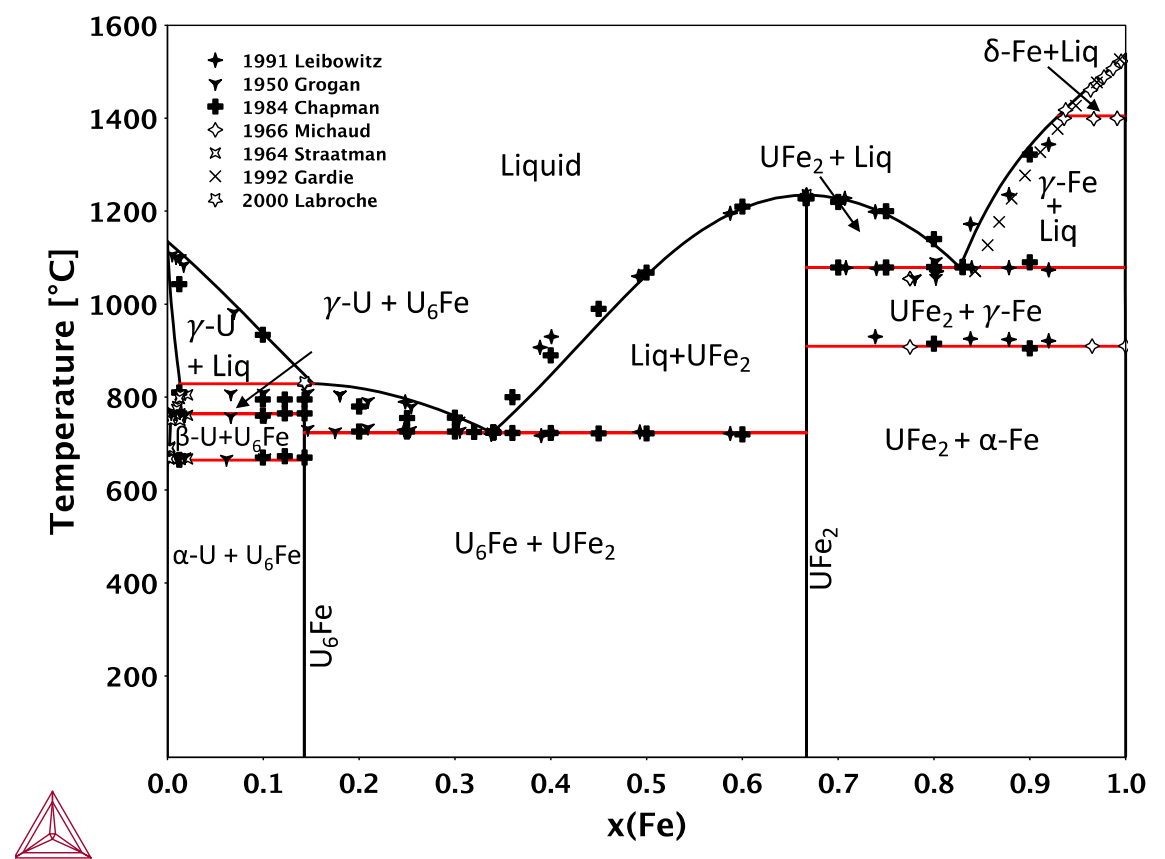

Figure 3. U-Fe phase diagram based on the present CALPHAD assessment compared with selected experimental data $[56,58-62,64]$.

The improved assessment includes better agreement for the congruent melting of $\mathrm{UFe}_{2}$ compared to Kurata [3] and Chatain [4], as well as some adjustments to the eutectic temperatures. Similarly, the eutectoid reaction $\left[\gamma-\mathrm{U} \leftrightarrow \beta-\mathrm{U}+\mathrm{U}_{6} \mathrm{Fe}\right]$ was improved with respect to $\mathrm{U}$-composition. The peritectic reaction (reaction 20, Table 5) temperature was updated to include the most recent measurements by [64], which was also considered in the works by Chatain et al. [4], but neglected in the most recent assessment by Kurata [3]. This CALPHAD assessment is in good agreement for the formation enthalpies for both compounds ( $\mathrm{UFe}_{2}$ and $\left.\mathrm{U}_{6} \mathrm{Fe}\right)$ when compared to literature and the values calculated by DFT from this work, which were used initial points for the fit.

\subsection{Fe-Ga Assessment}

This is the first published CALPHAD assessment of the Fe-Ga system (Figure 4), based on a preliminary internal report by coauthors [7]. Since ordering of the iron-rich side is not pertinent to the scope of this investigation and given the uncertainties reported in experimental studies [65-67], it is therefore not considered at this time. However, the overall shape of the phase diagram is reproduced in the present work, relevant invariant reactions and stoichiometric compounds are included, and improvements to the preliminary work of Turchi et al. [7] have been made so that some of the invariant reactions are better represented. This includes adjustments to the peritectic reaction of $\mathrm{Fe}_{3} \mathrm{Ga}_{4}$, where the reaction temperature is improved by $30{ }^{\circ} \mathrm{C}$ compared to [7] and the composition is in better agreement with experiments by [65-67]. Similarly, reaction temperatures and composition ranges are improved for reactions 3 and 5 in Table 5, however the best fit of experimental data resulted in a eutectic instead of a peritectic reaction for reaction 3. Major modifications to the liquidus and solidus ranges result in a more acceptable fit compared to the preliminary assessment. Since the $\alpha$-Fe (BCC_A2) phase is considered without any possible ordering, some disagreement on the Fe-rich side is to be expected. While the literature review (presented above) includes adequate descriptions of the ordering of $\alpha^{\prime}$-Fe, $\alpha^{\prime \prime}$-Fe and $\alpha^{\prime \prime \prime}$-Fe ( $\mathrm{Fe}_{3} \mathrm{Ga}$ composition dependence), it is to be noted that experiments proved difficulty in achieving equilibrium conditions in this phase space, which supports the current decision to exclude ordering on Fe-rich side. Similarly, the focus is on small amounts of Fe-impurities, therefore, only stoichiometric compositions were presented for each of the compounds and parameters for any ordered iron phase were neglected. This provided some difficulty when optimizing this region of the 
phase diagram and further investigation would be useful. The liquid phase is modeled using three interaction parameters, two of them temperature dependent. Even with multiple parameters, the liquidus curve on the Ga-rich side is difficult to reproduce due to the sharp decrease close to 100 at.\% $\mathrm{Ga}$. As additional terms or parameters for the liquid phase do not lead to significant improvement, the authors believe that including ordering for the BCC phase is necessary to have a better representation on the liquidus and solidus line across the phase diagram. Otherwise, this work shows rather acceptable improvements over the preliminary assessment of [7] and is a satisfactory representation of the Fe-Ga phase equilibria as seen experimentally.

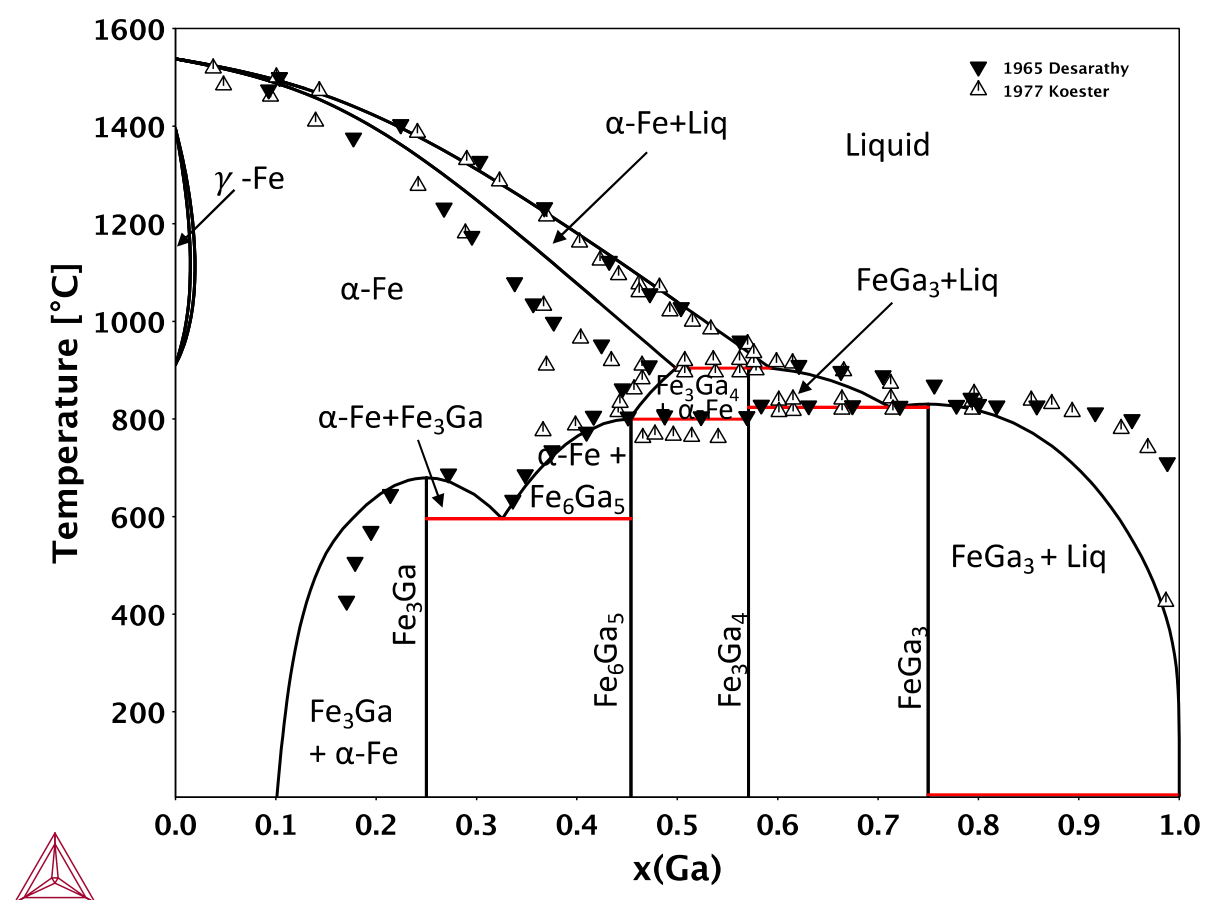

Figure 4. Calculated Fe-Ga phase diagram based on the present CALPHAD assessment and compared with experimental data [65-67].

\subsection{Pu-U-Fe Assessment}

The binary Pu-Fe and U-Fe reassessed parameters were used to extrapolate to the ternary Pu-U-Fe system, where some ternary interaction parameters were necessary to improve agreement with experiments. The most recent work of Kurata et al. [3] included an assessment of both the Pu-Fe and U-Fe binary, but did not cover the Pu-U-Fe ternary system. A prior assessment by the same authors [2] includes ternary Pu-U-Fe parameters, however their binary descriptions are not consistent with their most up to date publications [3]. Therefore, a new consistent assessment based on the newly assessed binary parameters presented in this study was necessary to properly fit the experimental data presented by [2]. The calculated phase diagram for the available isotherm at $650{ }^{\circ} \mathrm{C}$ is depicted in Figure 5 and compared with experimental data points reported by Kurata et al. [2]. The current assessment shows improvement over the binary extrapolation and includes more detailed description of the An-rich corners, which was previously lacking. Some enhancements in the tie-lines compared previous work is achieved on the U-rich corner, however the fit of the Liquid $\leftrightarrow(\mathrm{Pu}, \mathrm{U}) \mathrm{Fe}_{2}$ equilibrium could be improved by providing more experimental data on the Pu-rich side. The adjustment of further ternary parameters proved excessive without much improvement compared to the model of [2]. The same phase diagram is also calculated at room temperature, with the Pu-rich corner shown for clarity (Figure 6). Figure $6 \mathrm{~b}$ shows that $\mathrm{Pu}$-rich alloys include the $(\mathrm{Pu}, \mathrm{U})_{6} \mathrm{Fe}$ intermetallic as well as low temperature $\zeta$-phase (from the Pu-U system), with both of these phases consuming the $\alpha$-Pu matrix as a function of increased $U$ content, whereas Fe leads to the formation of a second intermetallic $(\mathrm{Pu}, \mathrm{U}) \mathrm{Fe}_{2}$. 


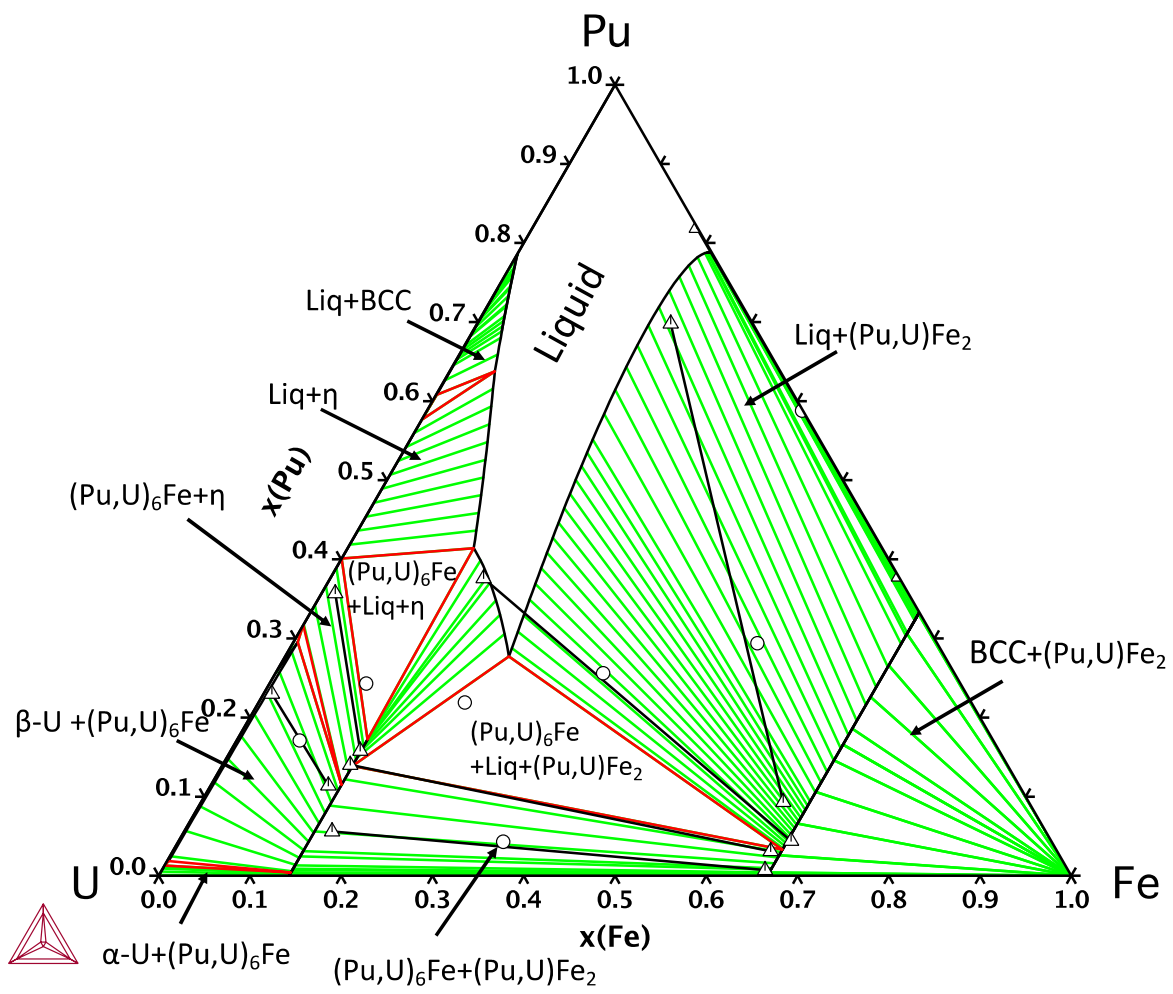

Figure 5. Calculated Pu-U-Fe phase diagram at $650{ }^{\circ} \mathrm{C}$ based on the present CALPHAD assessment compared to experiment [75].

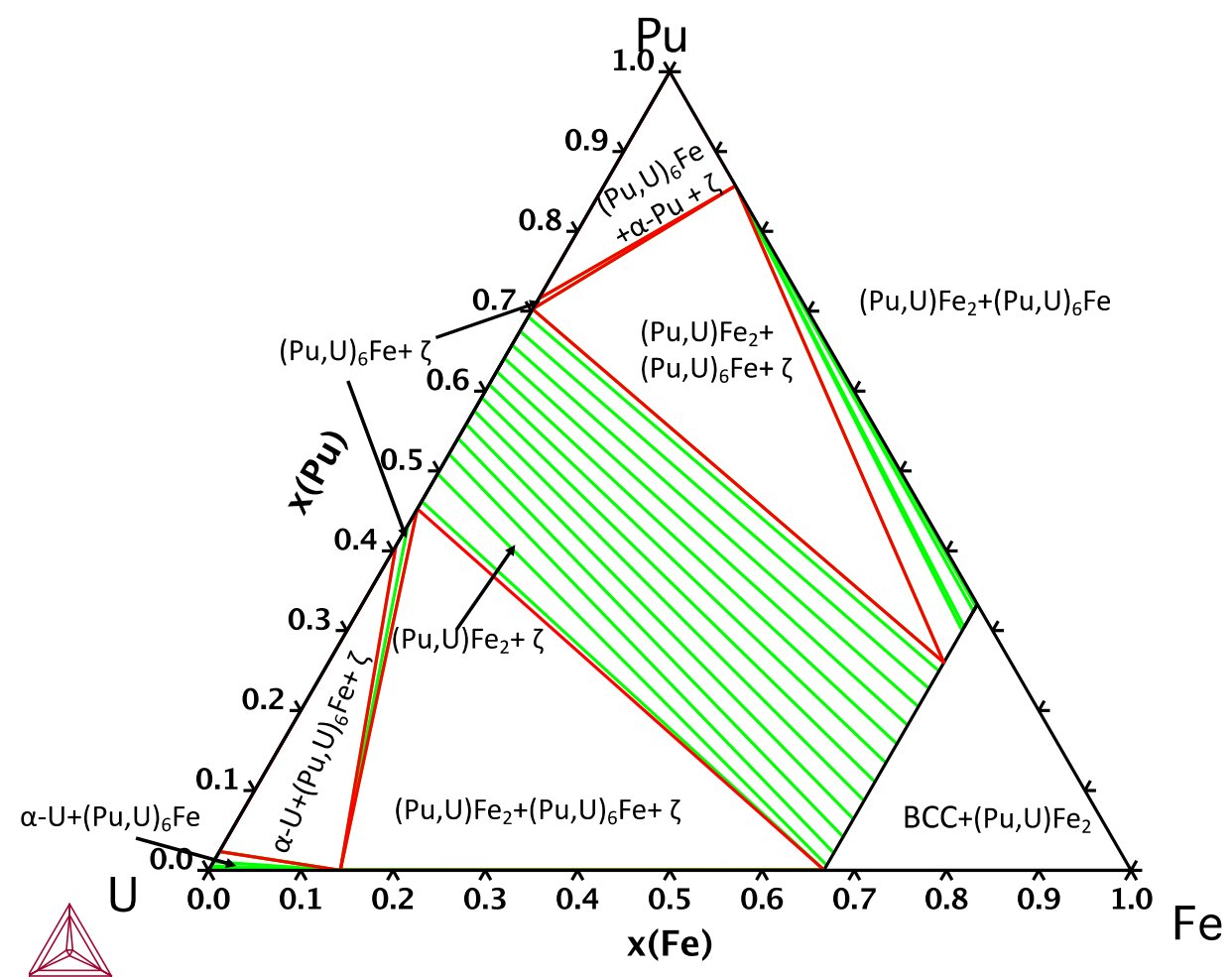

(a)

Figure 6. Cont. 


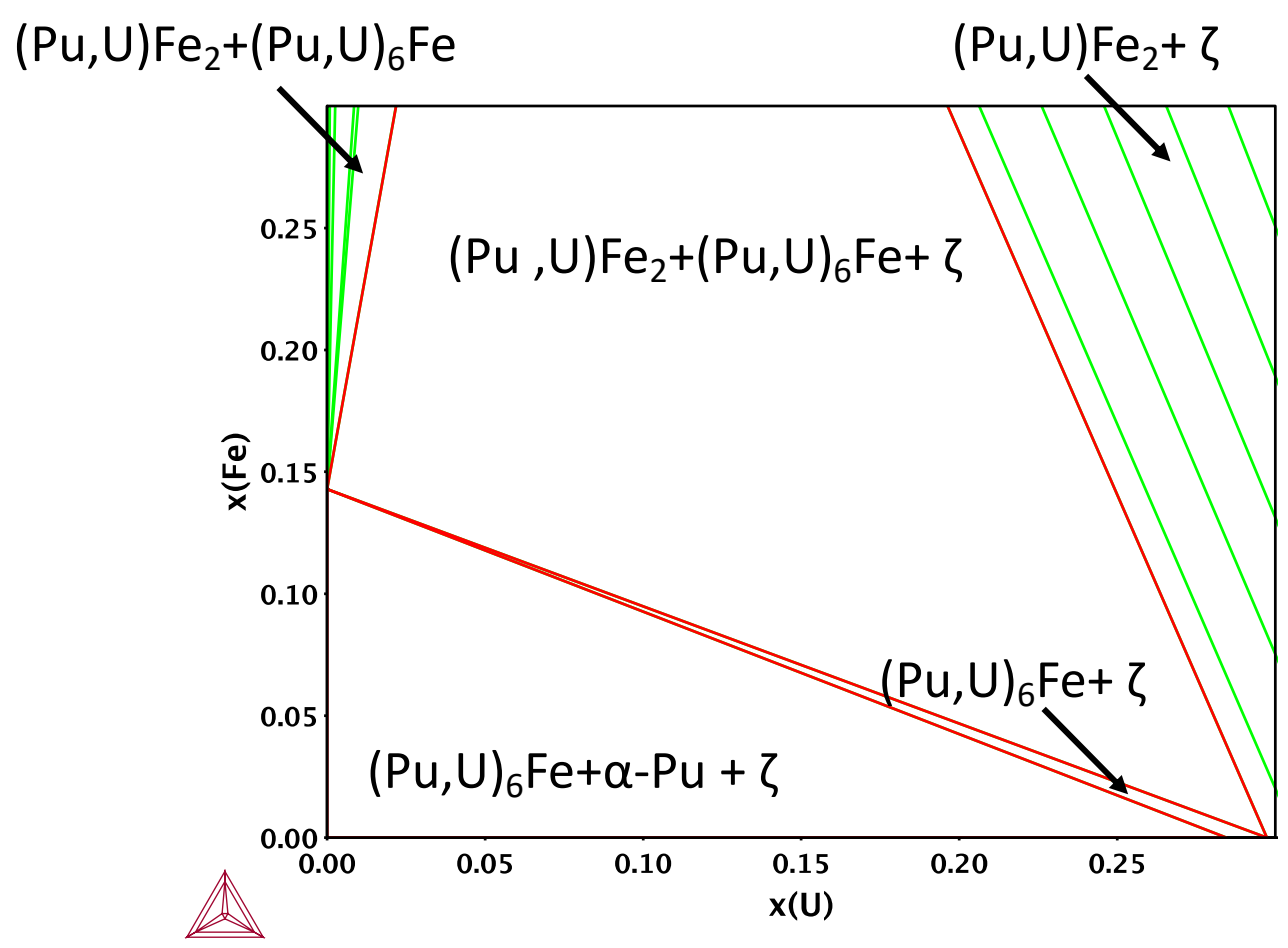

(b)

Figure 6. Calculated (a) Pu-U-Fe ternary section at room temperature with (b) a magnification of the Pu-rich part based on the present CALPHAD assessment.

\subsection{Extrapolation to $A n-F e-G a$ Systems $(A n=P u, U)$}

The extrapolation to the Pu-Fe-Ga and U-Fe-Ga systems are indicated at $1000{ }^{\circ} \mathrm{C}$ and room temperature in Figures 7-9. In the Pu-Fe-Ga system, there are no additional known ternary compounds so that the predicted phase diagrams are constructed via extrapolation of the pertinent binary systems. While there are some known intermetallics in the U-Fe-Ga system, there is no thermodynamic information about their stability above room temperature as all these compounds have been studied at $\mathrm{T}<25{ }^{\circ} \mathrm{C}$ for magnetic purposes as indicated in the literature review. They are therefore not considered in this work, however, future experiments on these compounds would be useful for thermodynamic assessments. The Pu-Fe-Ga phase diagram is plotted at $100{ }^{\circ} \mathrm{C}$ in Figure 7; phases from the binary systems which are stable at high temperature phases such as $\alpha$-Fe (BCC), $\gamma$-Fe (FCC) and the $\mathrm{PuFe}_{2}$ intermetallic, and $\mathrm{Pu}-\mathrm{Ga}$ compounds are among the first to form from the liquid phase. The U-analogous diagram in Figure 8 shows similar phase formation with the addition of $\gamma$-U (BCC) being stable for the uranium rich portion. More importantly, the room temperature phase diagrams show the formation of both $\mathrm{Pu}_{6} \mathrm{Fe}$ and $\mathrm{U}_{6} \mathrm{Fe}$ intermetallics for the An-rich region of the $\mathrm{Pu}-\mathrm{Fe}-\mathrm{Ga}$ and U-Fe-Ga systems (Figure 9a,b), respectively, which are accompanied by An-Ga phases within the actinide matrix. Closer interpretation is given to the phase stability and formation with respect to temperature for two different alloy compositions in the following section. 


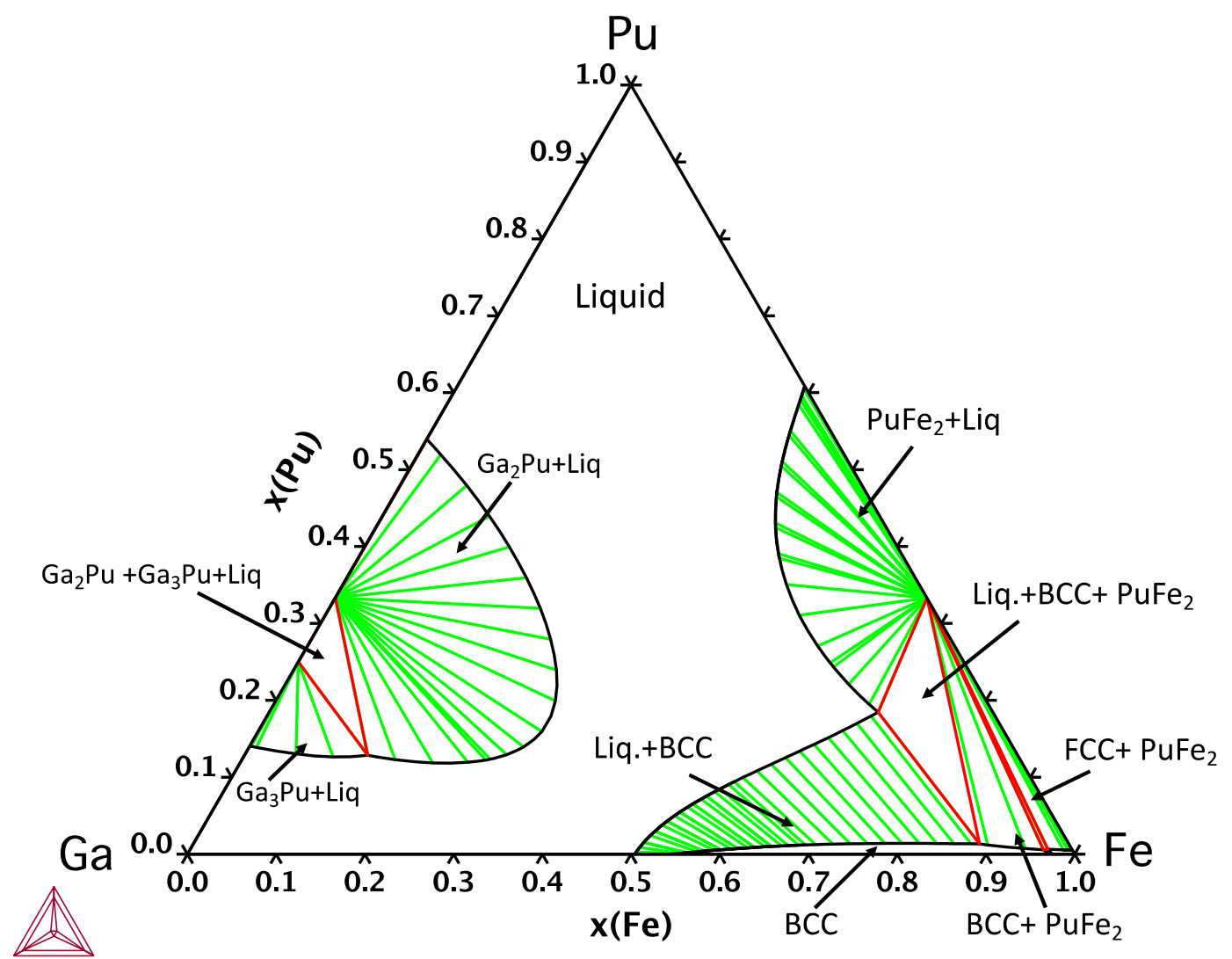

Figure 7. Pu-Fe-Ga ternary section at $1000^{\circ} \mathrm{C}$ based on the present CALPHAD assessment.

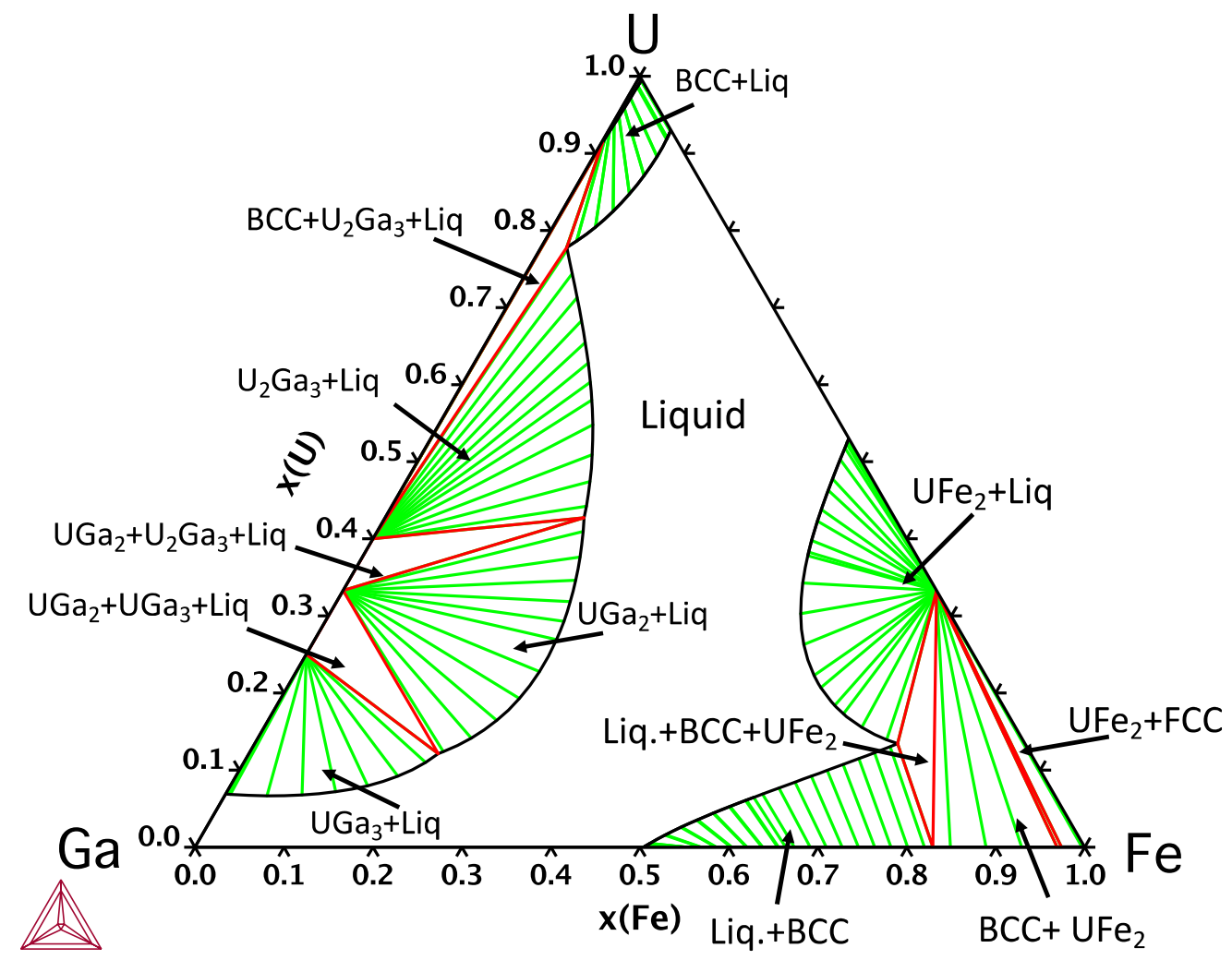

Figure 8. Calculated U-Fe-Ga ternary section at $1000{ }^{\circ} \mathrm{C}$ based on the present CALPHAD assessment. 


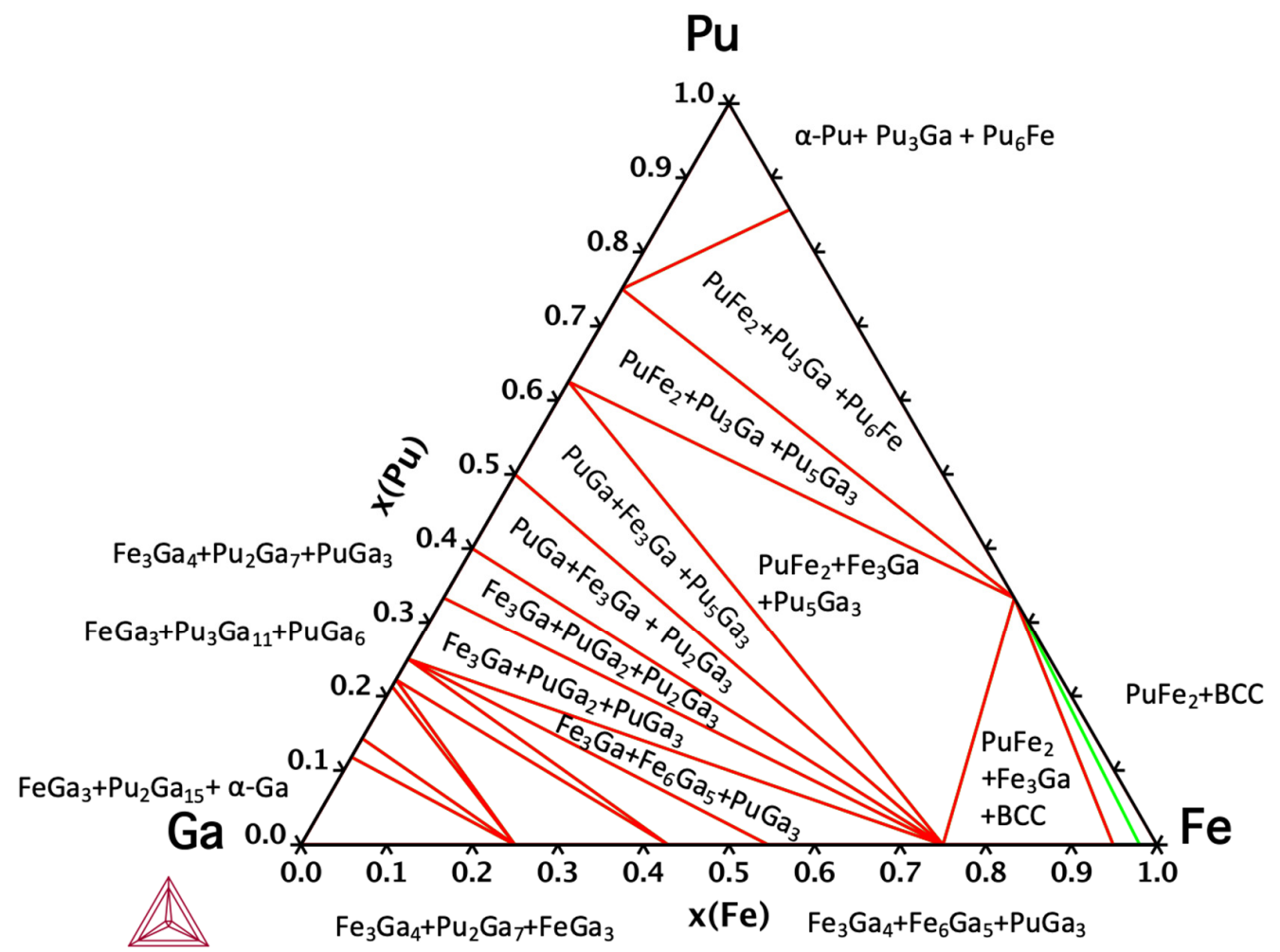

(a)

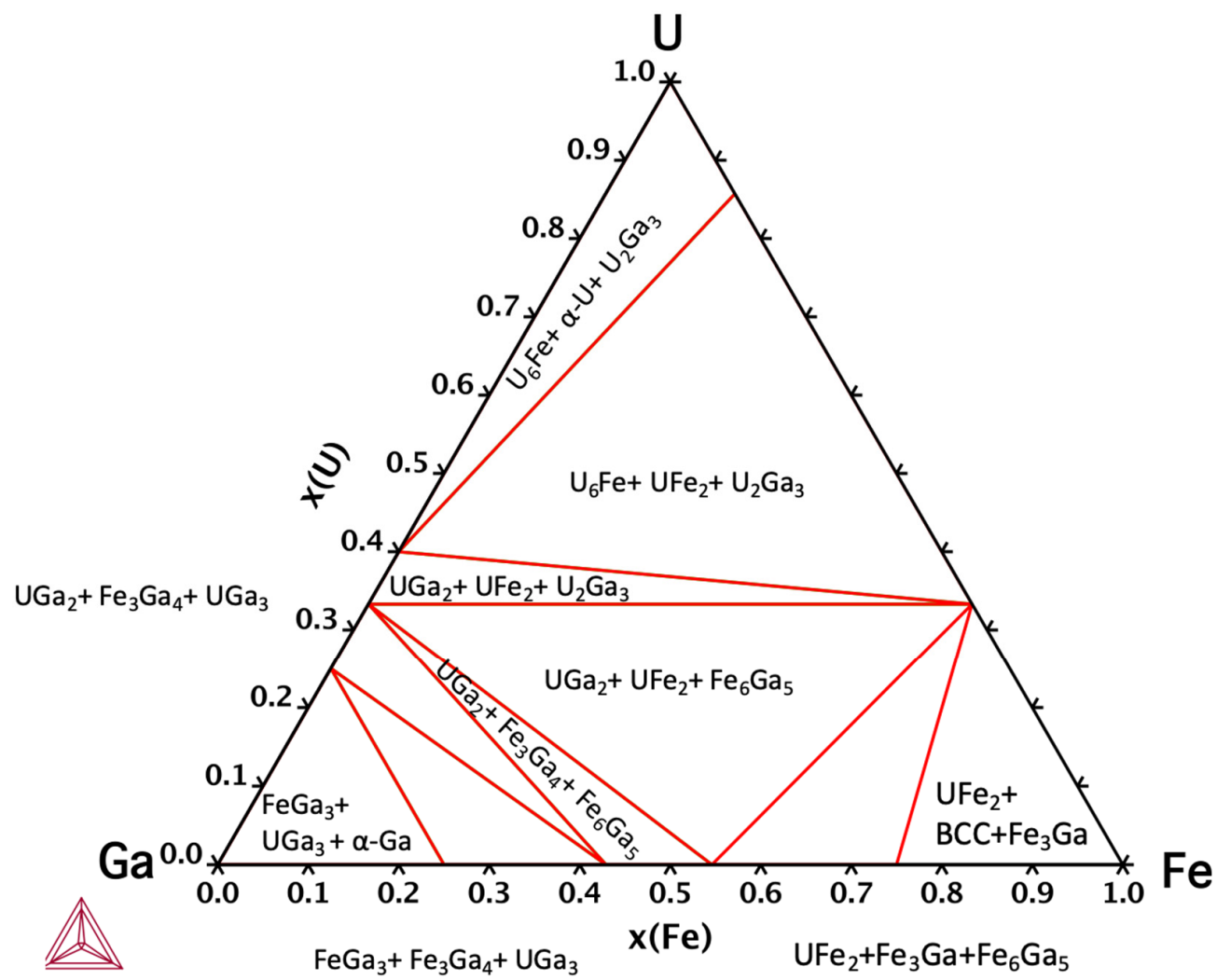

(b)

Figure 9. Calculated (a) Pu-Fe-Ga and (b) U-Fe-Ga ternary sections at room temperature based on the present CALPHAD assessments. 


\subsection{Prediction of Quaternary Pu-U-Fe-Ga System}

Two property diagrams are given to indicate the phase behavior of the quaternary system as function of temperature: $\mathrm{Pu}_{89}-\mathrm{U}_{5}-\mathrm{Ga}_{5}-\mathrm{Fe}_{1}$ and $\mathrm{Pu}_{92.9}-\mathrm{U}_{5}-\mathrm{Ga}_{2}-\mathrm{Fe}_{0.1}$ (at. \%). These calculations assume that Ga stabilizes the $\delta$-Pu phase down to room temperature (metastable state stabilized by the extremely slow eutectoid decomposition of $\delta$ - $\mathrm{Pu}$ into $\alpha$-Pu and $\mathrm{Pu}_{3} \mathrm{Ga}$ [94], therefore low temperature allotropes of $\mathrm{Pu}$ are not considered for the Ga concentration considered here ( 2 and 5 at. \%). All of the Ga is therefore contained within the FCC phase of $\delta$-Pu. In Figure $10\left(\mathrm{Pu}_{89}-\mathrm{U}_{5}-\mathrm{Ga}_{5}-\mathrm{Fe}_{1}\right)$, the predominant phases at room temperature are $\delta$-Pu, the $\zeta$-phase, which exists in the binary $\mathrm{Pu}-\mathrm{U}$ phase space, and the $(\mathrm{Pu}, \mathrm{U})_{6} \mathrm{Fe}$ intermetallic. The $\zeta$-phase exists at low temperatures and exhibits increasing uranium solubility with respect to temperature, extending up to almost 70 at. \% uranium at temperatures up to $588{ }^{\circ} \mathrm{C}$ [1] in the Pu-U system. It is this phase that accommodates most of the $\mathrm{U}$ from the alloy composition in Figure 10; a small remaining amount of uranium is contained in the $(\mathrm{Pu}, \mathrm{U})_{6} \mathrm{Fe}$ intermetallic, where the uranium solubility in the intermetallic slightly increases over a small temperature. As the latter phase disappears, the Fe is accommodated within another lower An-containing intermetallic $(\mathrm{Pu}, \mathrm{U}) \mathrm{Fe}_{2}$, with this phase accounting for slightly more $\mathrm{U}$ than $\mathrm{Pu}$. Once $(\mathrm{Pu}, \mathrm{U}) \mathrm{Fe}_{2}$ is saturated at its stoichiometric ratio, the remaining Pu released from $(\mathrm{Pu}, \mathrm{U})_{6} \mathrm{Fe}$ is reincorporated into the Pu-matrix as clearly indicated by the increase of $\delta$-Pu phase fraction in Figure 10. Finally, with the disappearance of the low temperature $\zeta$-phase, the Pu-U binary $\eta$-phase forms at higher temperatures, accommodating a larger amount of Pu leading to a sharp decrease in $\delta$-Pu. At $462{ }^{\circ} \mathrm{C}$ the first appearance of liquid occurs, indicative of the upper stability limit of $(\mathrm{Pu}, \mathrm{U}) \mathrm{Fe}_{2}$, which is accompanied by a decrease in the $\eta$-phase, resulting in an iron and uranium rich liquid. At $491^{\circ} \mathrm{C}$, the Pu-U binary $\eta$-phase transitions into a BCC solid solution of $\varepsilon$-Pu and $\gamma$-U, while $\delta$-Pu phase continues to transform into BCC $(\varepsilon-\mathrm{Pu})$ and eventually melts at $666^{\circ} \mathrm{C}$. It is interesting to note that even minor additions ( 1 at. \%) of iron induces a drastic decrease of the incipient melting point of the alloy by $195^{\circ} \mathrm{C}$, compared to $\mathrm{Pu}_{90}-\mathrm{U}_{5}-\mathrm{Ga}_{5}$. The evolution of the elemental distribution per phase is plotted as a function of temperature in Figure 11 for the $\mathrm{Pu}_{89}-\mathrm{U}_{5}-\mathrm{Ga}_{5}-\mathrm{Fe}_{1}$ alloy composition.

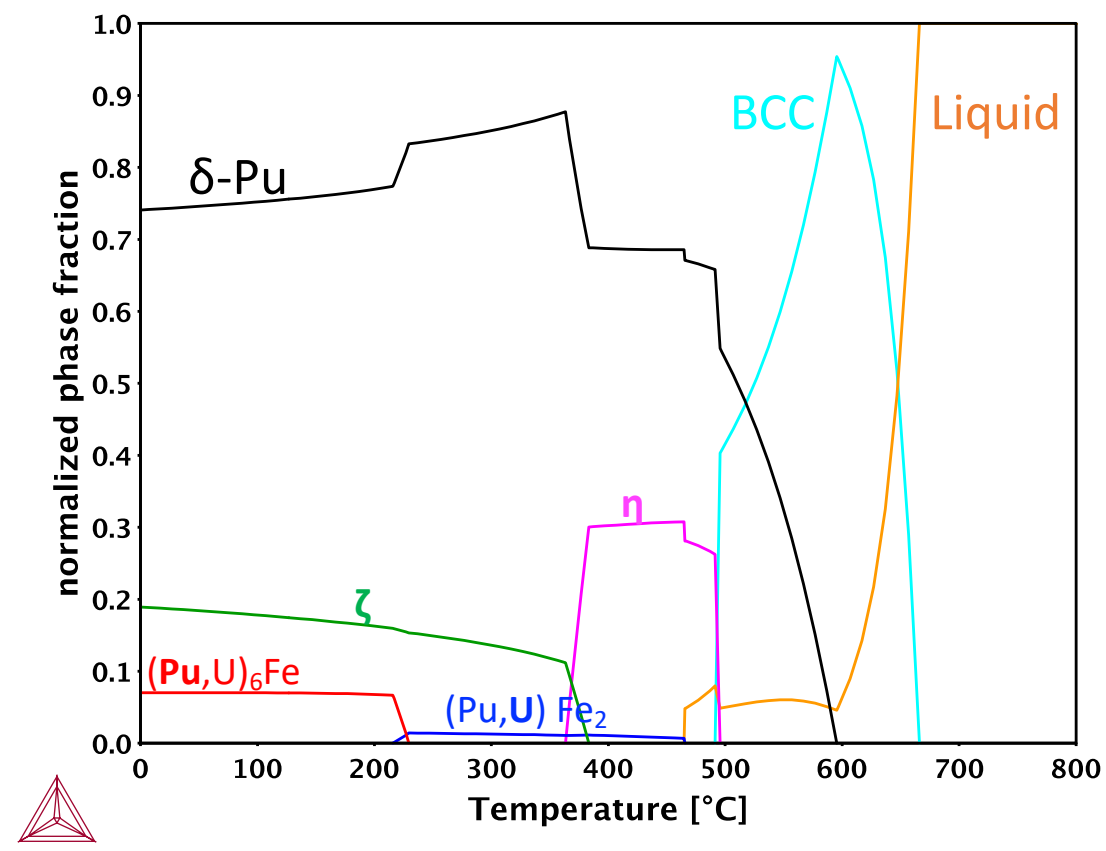

Figure 10. Property diagram of $\mathrm{Pu}_{89}-\mathrm{U}_{5}-\mathrm{Ga}_{5}-\mathrm{Fe}_{1}$ (at. \%) calculated using the present CALPHAD database. 

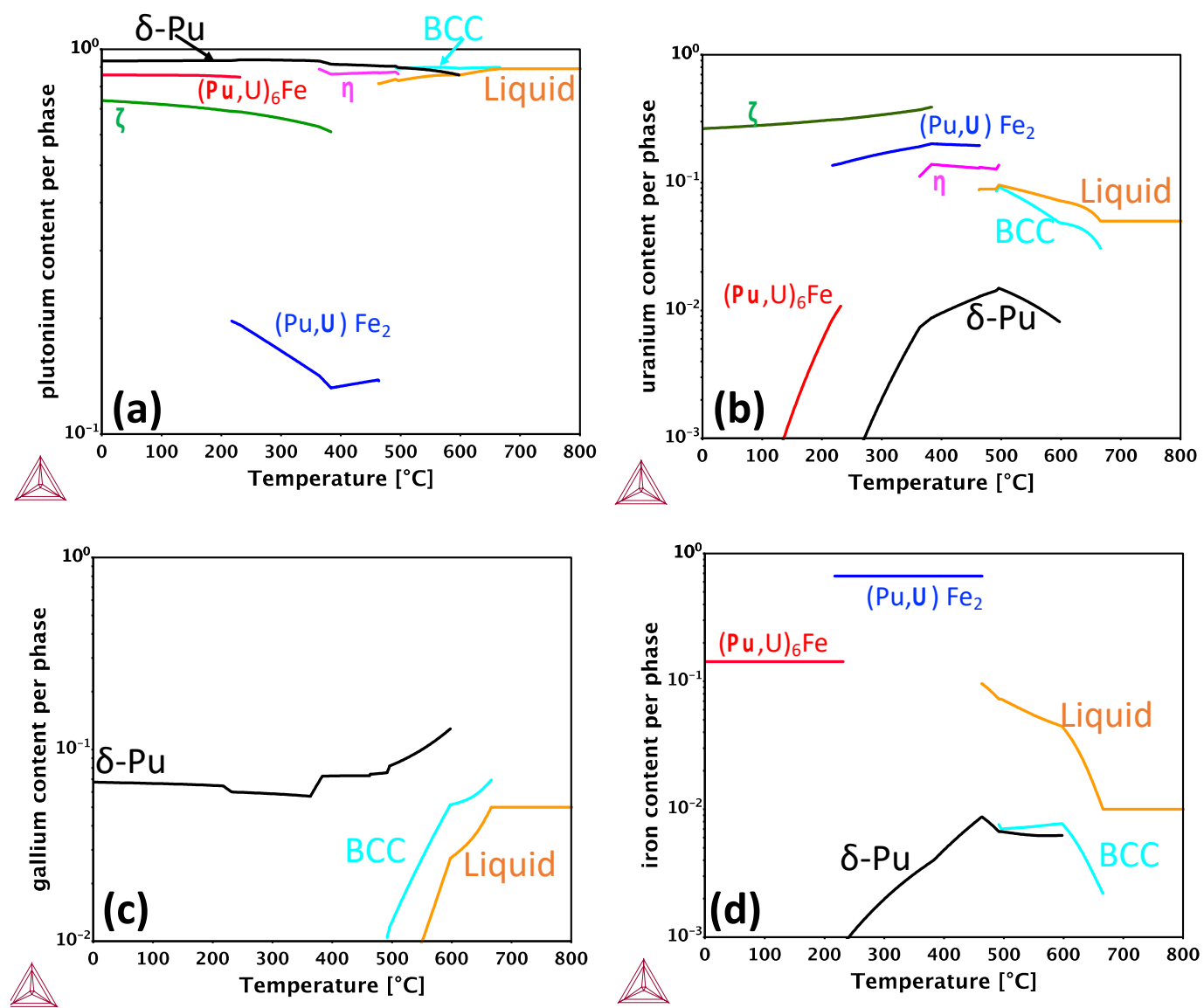

Figure 11. Distribution of elemental components within a given phase for the $\mathrm{Pu}_{89}-\mathrm{U}_{5}-\mathrm{Ga}_{5}-\mathrm{Fe}_{1}$ for (a) plutonium, (b) uranium, (c) gallium and (d) iron.

Figure 12 simulates an iron impurity of about $1000 \mathrm{ppm}$ with the atomic composition of $\mathrm{Pu}_{92.9} \mathrm{U}_{5}-\mathrm{Ga}_{2}-\mathrm{Fe}_{0.1}$. As with the previous property diagram, the three stable phases at room temperature are $\delta$-Pu, the $\zeta$-phase and $(\mathrm{Pu}, \mathrm{U})_{6} \mathrm{Fe}$. With small (trace) amounts of $\mathrm{Fe}$, only the An-rich intermetallic is formed. As the stability limit of $(\mathrm{Pu}, \mathrm{U})_{6} \mathrm{Fe}$ is reached as a function of temperature, the Fe becomes soluble in $\delta$-Pu which increases with temperature. The uranium in the alloy is either accommodated within the $\zeta$-phase at low temperature and $\eta$-phase at higher temperature. The formation of $\eta$-phase is able to include higher $\mathrm{Pu}$ content and therefore depletes $\delta$-Pu until the transition to $\varepsilon$-Pu around $483^{\circ} \mathrm{C}$ where the BCC lattice also accommodates $\gamma-\mathrm{U}$ and Fe until its melting point. 


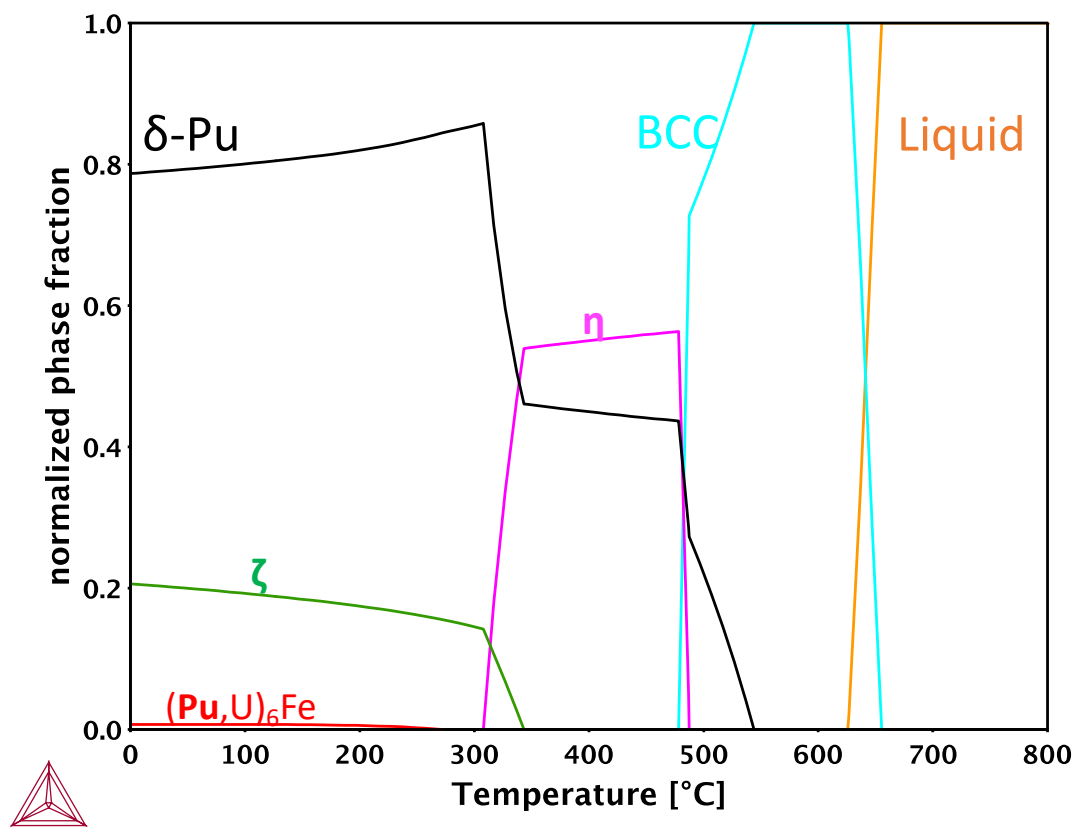

Figure 12. Property diagram of $\mathrm{Pu}_{92.9} \mathrm{U}_{5}-\mathrm{Ga}_{2}-\mathrm{Fe}_{0.1}$ (at. \%) calculated using the present CALPHAD database.

\section{Conclusions}

From the extensive literature review presented here, the Pu-Fe and U-Fe systems have been reassessed to include more details on the solubility of $\mathrm{Fe}$ in the actinide rich composition ranges. Density functional theory calculations of the formation enthalpy were performed to use for the CALPHAD optimizations for both intermetallic phases $\left(\mathrm{An}_{6} \mathrm{Fe}\right.$ and $\left.\mathrm{AnFe}_{2}\right)$. Pu-Fe and U-Fe assessments were improved to include a description of impurity level iron in the respective actinides. These binary assessments were used to reassess the Pu-U-Fe system, which is in agreement with available experimental data. A first CALPHAD assessment of the Fe-Ga phase diagram is presented, where the iron rich ordered phases are neglected. Finally, property diagrams were used to simulate alloys with varying Fe content to show the impact of impurities on Pu-U-Ga alloys. Experimental investigations of the Pu-Fe-Ga and U-Fe-Ga systems would be useful for future assessments.

Author Contributions: Conceptualization, E.E.M., P.E.A.T., B.O., S.A.S. and A.P.; Funding acquisition, J.L.B., S.A.S. and A.P.; Investigation, E.E.M., A.L. and P.S.; Project administration, P.E.A.T., J.L.B., S.A.S. and A.P.; Supervision, A.P.; Validation, E.E.M.; Writing—original draft, E.E.M., A.L. and P.S.; Writing一review \& editing, E.E.M., P.E.A.T., B.O., J.L.B., S.A.S. and A.P.

Funding: This research received no external funding.

Acknowledgments: This work was performed under the auspices of the U.S Department of Energy by Lawrence Livermore National Laboratory under contract DE-AC52-07NA27344. This work was done as part of the international agreement on cooperation between DOE-NNSA and CEA-DAM in fundamental science supporting stockpile stewardship.

Conflicts of Interest: The authors declare no conflict of interest.

\section{References}

1. Perron, A.; Turchi, P.E.A.; Landa, A.; Söderlind, P.; Ravat, B.; Oudot, B.; Delaunay, F.; Kurata, M. Thermodynamic re-assessment of the Pu-U system and its application to the ternary Pu-U-Ga system. J. Nucl. Mater. 2014, 454, 81-95. [CrossRef]

2. Kurata, M.; Nakamura, K.; Ogata, T. Thermodynamic evaluation of the quaternary U-Pu-Zr-Fe system-assessment of cladding temperature limits of metallic fuel in a fast reactor. J. Nucl. Mater. 2001, 294, 123-129. [CrossRef] 
3. Kurata, M. Thermodynamic database on U-Pu-Zr-Np-Am-Fe alloy system II- Evaluation of Np, Am and Fe containing systems. In Proceedings of the IOP Conference Series: Material Science and Engineering, San Francisco, CA, USA, 12-17 July 2009. [CrossRef]

4. Chatain, S.; Guéneau, C.; Labroche, D. Thermodynamic assessment of the Fe-U binary system. J. Phase Equilib. 2003, 24, 122-131. [CrossRef]

5. Wang, J.; Liu, Z.J.; Wang, C.P. Thermodynamic calculation of phase equilibria of the U-Ga and U-W systems. J. Nucl. Mater. 2008, 380, 105-110. [CrossRef]

6. Moussa, G.; Berche, A.; Barbosa, J.; Pasturel, M.; Stepnik, B.; Tougait, O. Experimental investigation of the phase equilibria and thermodynamic assessment in the U-Ga and U-Al-Ga systems. J. Nucl. Mater. 2018, 499, 361-371. [CrossRef]

7. Turchi, P.E.A.; Kaufman, L.; Liu, Z.-K.; Zhou, S. Thermodynamics and Kinetics of Phase Transformations in Plutonium Alloys-Part 1; UCRL-TR-206658; Lawrence Livermore National Lab.: Livermore, CA, USA, 2004.

8. Lukas, H.L.; Fries, S.G.; Sundman, B. Computational Thermodynamics, The Calphad Method; Cambridge University Press: New York, NY, USA, 2007.

9. Dinsdale, A.T. SGTE data for pure elements. Calphad 1991, 15, 317-425. [CrossRef]

10. Redlich, O.; Kister, A.T. Algebraic representation of thermodynamic properties and the classification of solutions. Ind. Eng. Chem. 1948, 40, 345-348. [CrossRef]

11. Muggianu, Y.; Gambino, M.; Bros, J. Enthalpies of formation of liquid alloys bismuth-gallium-tin at 723 $\mathrm{K}$-Choice of an analytical representation of integral and partial thermodynamic functions of mixing for this ternary system. J. Chim. Phys. Phys-Chim. Biol. 1975, 72, 83-88. [CrossRef]

12. Hohenberg, P.; Kohn, W. Inhomogeneous Electron Gas. Phys. Rev. 1964, 136, B864-B871. [CrossRef]

13. Kohn, W.; Sham, L. Self-Consistent Equations Including Exchange and Correlation Effects. Phys. Rev. 1965, 140, A1133-A1338. [CrossRef]

14. Söderlind, P.; Gonis, A. Assessing a solids-biased density-gradient functional for actinide metals. Phys. Rev. B 2010, 82, 033102. [CrossRef]

15. Perdew, J.P. Electronic Structures of Solids; Ziesche, P., Eschrig, H., Eds.; Springer: Berlin, Germany, 1991; pp. 11-20.

16. Perdew, J.P.; Ruzsinszky, A.; Gabor, G.O.; Vydrov, O.A.; Scuseria, G.E.; Constantin, L.A.; Zhou, X.; Kieron, B. Restoring the Density-Gradient Expansion for Exchange in Solids and Surfaces. Phys. Rev. Lett. 2008, 100, 136406. [CrossRef] [PubMed]

17. Savrasov, S.Y.; Kotliar, G. Ground-State Theory of $\delta$-Pu. Phys. Rev. Lett. 2000, 84, 3670-3673. [CrossRef] [PubMed]

18. Söderlind, P.; Landa, A.; Sadigh, B. Density-functional theory for plutonium. Adv. Phys. 2019, 68, 1-47. [CrossRef]

19. Xie, W.; Xiong, W.; Marianetti, C.A.; Morgan, D. Correlation and relativistic effects in U metal and U-Zr alloy: Validation of ab initio approaches. Phys. Rev. B 2013, 88, 235128. [CrossRef]

20. Söderlind, P.; Landa, A.; Turchi, P.E.A. Comment on "Correlation and relativistic effects in U metal and U-Zr alloy: Validation of ab initio approaches". Phys. Rev. B 2014, 90, 157101. [CrossRef]

21. Wills, J.M.; Alouani, M.; Andersson, P.; Delin, A.; Eriksson, O.; Grechnev, O. Full Potential Electronic Structure Method; Springer: Berlin, Germany, 2010.

22. Söderlind, P. Theory of the crystal structures of cerium and the light actinides. Adv. Phys. 1998, 47, 959-998. [CrossRef]

23. Söderlind, P.; Grabowski, B.; Yang, L.; Landa, A.; Björkman, T.; Souvatzis, P.; Eriksson, O. High-temperature phonon stabilization of $\gamma$-uranium from relativistic first-principles theory. Phys. Rev. B 2012, 85, 060301. [CrossRef]

24. Vitos, L.; Abrikosov, I.A.; Johansson, B. Anisotropic Lattice Distortions in Random Alloys from First-Principals Theory. Phys. Rev. Lett. 2001, 87, 156401. [CrossRef]

25. Vitos, L. Computational Quantum Mechanics for Materials Engineers: The EMTO Method and Application; Springer: London, UK, 2007.

26. Kollar, J.; Vitos, L.; Skriver, H.L. Electronic Structure and Physical Properties in Solids: The Uses of the LMTO Method; Springer: Berlin, Germany, 2000; pp. 85-113.

27. Perdew, J.P.; Burke, K.; Ernzerhof, M. Generalized Gradient Approximation Made Simple. Phys. Rev. Lett. 1996, 77, 3865-3868. [CrossRef] 
28. Monkhorst, H.P.J. Special points for Brillouin-zone integrations. Phys. Rev. B 1976, 13, 5188-5192. [CrossRef]

29. Landa, A.; Söderlind, P.; Turchi, P.E.A. Density-functional study of the U-Zr system. J. Alloy Compd. 2009, 478, 103-110. [CrossRef]

30. Landa, A.; Söderlind, P.; Turchi, P.E.A.; Vitos, L.; Ruban, A. Density-functional study of Zr-based actinide alloys: 2. U-Pu-Zr system. J. Nucl. Mater. 2009, 393, 141-145. [CrossRef]

31. Landa, A.; Söderlind, P.; Turchi, P.E.A.; Vitos, L.; Ruban, A. Density functional study of Zr-based actinide alloys. J. Nucl. Mater. 2009, 385, 68-71. [CrossRef]

32. Landa, A.; Söderlind, P.; Turchi, P.E.A.; Vitos, L.; Ruban, A. Density-functional study of bcc Pu-U, Pu-Np, Pu-Am, Pu-Cm alloys. J. Nucl. Mater. 2009, 408, 61-66. [CrossRef]

33. Bajaj, S.; Garay, A.; Landa, A.; Söderlind, P.; Turchi, P.E.A.; Arróyave, R. Thermodynamic study of the Np-Zr system. J. Nucl. Mater. 2011, 409, 1-8. [CrossRef]

34. Landa, A.; Söderlind, P.; Turchi, P.E.A. Density-functional study of bcc U-Mo, Np-Mo, Pu-Mo, and Am-Mo alloys. J. Nucl. Mater. 2013, 434, 31-37. [CrossRef]

35. Turchi, P.E.A.; Landa, A.; Söderlind, P.A. Thermodynamic assessment of the Am-Pu system with input from ab initio. J. Nucl. Mater. 2011, 418, 165-173. [CrossRef]

36. Bajaj, S.; Söderlind, P.; Turchi, P.E.A.; Arróyave, R. The U-Ti system: Strengths and weaknesses of the CALPHAD method. J. Nucl. Mat. 2011, 419, 177-185. [CrossRef]

37. Perron, A.; Turchi, P.E.A.; Landa, A.; Söderlind, P.; Ravat, B.; Oudot, B.; Delaunay, F. The Pu-U-Am system: An ab initio informed CALPHAD thermodynamic study. J. Nucl. Mater. 2015, 458, 425-441. [CrossRef]

38. Turchi, P.E.A.; Kaufman, L.; Zhou, S.; Liu, Z.-K. Thermostatics and kinetics of transformations in Pu-based alloys. J. Alloy Compd. 2007, 444, 28-35. [CrossRef]

39. Perron, A.; Ravat, B.; Oudot, B.; Lalire, F.; Mouturat, K.; Delaunay, F. Phase transformations in Pu-Ga alloy: Synergy between simulations and experiments to elucidate direct and indirect reversion competition. Acta Mater. 2013, 61, 7109-7120. [CrossRef]

40. Ravat, B.; Oudot, B.; Perron, A.; Lalire, F.; Delaunay, F. Phase transformations in PuGa 1 at. \% alloy: Study of whole reversion process following martensitic transformation. J. Alloy Compd. 2013, 580, 298-309. [CrossRef]

41. Ravat, B.; Lalire, F.; Oudot, B.; Appolaire, B.; Aeby-Gautier, E.; Panisiot, J.; Delaunay, F. Phase transformations in PuGa 1 at. \% alloy: Influence of stress on $\delta \rightarrow \alpha^{\prime}$ martensitic transformation at low temperatures. Materialia 2019, 6, 100304. [CrossRef]

42. Perron, A.; Turchi, P.E.A.; Landa, A.; Oudot, B.; Ravat, B.; Delaunay, F. Thermodynamic assessments and inter-relationships between systems involving Al, Am, Ga, Pu and U. J. Nucl. Mater. 2016, 482, 187-200. [CrossRef]

43. Konobeevsky, S.T. Phase Diagram of Some Plutonium Systems, Conference on the Peaceful Use of Atomic Energy, Moscow, Soviet Union, 1955.

44. Avivi, E. Studies of Plutonium-Iron and Uranium-Plutonium-Iron Alloys. Doctorate Thesis/Dissertation, CEA-Fontenay-aux-Roses, Université de Paris, Paris, France, 1964.

45. Mardon, P.G.; Haines, H.R.; Pearce, J.H.; Waldron, M.B. The Plutonium-Iron system. J. Inst. Met. 1957, 86, 166-171.

46. Ofte, D.; Wittenberg, L.J. Viscosity-Composition Relationships in Molten Plutonium-Iron Alloys. Trans. ASM 1964, 57, 916-924.

47. Chiotti, P.; Akhachinskij, V.V.; Ansara, I.; Rand, M.H. The Chemical Thermodynamics of Actinide Elements and Compounds; International Atomic Energy Agency: Vienna, Austria, 1981; pp. 114-117, 228-230.

48. Campbell, G. Plutonium and Other Actinides; Blanck, H., Lindner, R., Eds.; North Holland: Amsterdam, The Netherlands, 1976.

49. Akhachinskij, V.V.; Koputin, L.M.; Ivanov, I.; Podol'skaya, N.S. Thermodynamics of Nuclear Materials. In Proceedings of the Symposium on Thermodynamics of Nuclear Materials, Vienna, Austria, 21-25 May 1962.

50. Schonfeld, F.W. Plutonium Phase Diagrams Studied at Los Alamos; Coffinberry, A.S., Miner, W.N., Eds.; University of Chicago Press: Chicago, IL, USA, 1961.

51. Elliott, R.O.; Larson, A.C. The Metal Plutonium; Coffinberry, A.S., Miner, W.N., Eds.; University of Chicago Press: Chicago, IL, USA, 1961; pp. 265-280.

52. Schwartz, D.S.; Tobash, P.H.; Richmond, S. Thermal Analysis of Pu ${ }_{6} F e$ Synthesized from Hydride Precursor; Material Research Society: San Francisco, CA, USA, 2014.

53. Moreau, G.; Calais, D. Solubility of Plutonium in Iron. J. Nucl. Mater. 1967, 24, 121-124. [CrossRef] 
54. Okamoto, H. Phase Diagrams of Binary Actinide Alloys; Kassner, M.E., Peterson, D.E., Eds.; ASM International: Materials Park, OH, USA, 1995; pp. 314-317.

55. Gordon, P.; Kaufmann, A.R. Uranium-Aluminum and Uranium-Iron. Trans. Metall. AIME 1950, 188, $182-194$.

56. Grogan, J.D. The Uranium-Iron System. J. Inst. Met. 1950, 77, 571-576.

57. Bellot, J.; Blanchon, A.; Chazot, R.; Dosiere, P.; Henry, J.-M.; Colas, M. Uranium-Iron Equilibrium Diagram for Dilute Iron Concentration Range. C. R. 1958, 246, 3063-3065.

58. Straatman, J.A.; Neumann, N.F. Equilibrium Structures in the High Uranium-Iron Alloy System; Topical Report. No. MCW-1487 MCW-1487; Mallinckrodt Chemical Works: Welding Spring, Missouri, USA, 1964.

59. Michaud, G.G. A study of the iron-rich portion of the Fe-U phase diagram. Can. Metall. Q. 1966, 5, 355-365. [CrossRef]

60. Chapman, L.R.; Holcombe, C.F. Revision of the Uranium-Iron Phase Diagram. J. Nucl. Mater. 1984, 126, 323-326. [CrossRef]

61. Leibowitz, L.; Blomquist, R.A. Thermodynamics and Phase Equilibria of the Iron-Uranium System. J. Nucl. Mater. 1991, 184, 47-52. [CrossRef]

62. Gardie, P.; Bordier, G.; Poupeau, J.J.; Le Ny, J. Thermodynamic Activity Measurements of U-Fe and U-Ga Alloys by Mass Spectrometry. J. Nucl. Mater. 1992, 189, 85-96. [CrossRef]

63. Swindells, N. The Solubility of Iron in Solid Uranium Between 0.003 wt. \% and 0.3 wt. \% Iron. J. Nucl. Mater. 1966, 18, 261-271. [CrossRef]

64. Labroche, D. Contribution a l'etude Thermodynamique du Systeme Ternaire U-Fe-O. Ph.D. Thesis/Dissertation, Institut National Polytechnique de Grenoble, Grenoble, France, 2000.

65. Dasarathy, C.; Hume Rothery, W. The system iron-gallium. Proc. R. Soc. Lond. Ser. A 1965, 286, $141-157$.

66. Köster, W.; Gödecke, T. Über den Aufbau des Systems Eisen-Gallium zwischen 10 und 50 At.-\% Ga und dessen Abhägigkeit von der Wärmebehandlung, I. Das Diagramm der raumzentrierten Phasen. Z. Metallk. 1977, 68, 582-589.

67. Köster, W.; Gödecke, T. Über den Aufbau des Systems Eisen-Gallium z zwischen 10 und 50 At.- $\%$ Ga und dessen Abhägigkeit von der Wärmebehandlung II. Das Gleichgewichtsdiagramm. Z. Metallk. 1977, 68, 661-666.

68. Luo, H.L. Lattice Parameters of Iron-Rich Iron-Gallium Alloys. Trans. Metall. AIME 1967, 239, 119-120.

69. Malaman, B.; Philippe, M.J.; Roques, B.; Courtois, A.; Protas, J. Structures cristallines des phases $\mathrm{Fe}_{6} \mathrm{Ge}_{5}$ et $\mathrm{Fe}_{5} \mathrm{Ga}_{5}$. Acta Crystallogr. B 1974, 30, 2081-2087. [CrossRef]

70. Meissner, H.G.; Schubert, K. Constitution of Some Systems Homologous and Quasihomologous to T ${ }^{5}$-Ga, II. The Systems Chromium-Gallium, Manganese-Gallium, and Iron-Gallium and some Notes on the Systems Vanadium-Antimony and Vanadium-Arsenic. Z. Metallk. 1965, 56, 523-530.

71. Schubert, K.; Bhan, S.; Burkhart, W.; Gohle, R.; Meissner, H.G.; Poetschke, M.; Stolz, E. Structural Data on Metallic Phases. Naturwissenschaften 1960, 47, 303. [CrossRef]

72. Okamoto, H. Binary Alloy Phase Diagrams, 2nd ed.; Massalski, T.B., Okamoto, H., Subramnian, P.F., Kacprzak, L., Eds.; ASM International: Materials Park, OH, USA, 1993.

73. Ogata, T.; Nakamura, K.; Kurata, M.; Yokoo, T.; Mignanelli, M.A. Reactions between U-Pu-Zr Alloys and Fe at 923 K. J. Nucl. Sci. Technol. 2000, 37, 244-252. [CrossRef]

74. Nakamura, K.; Ogata, T.; Kurata, M.; Yokoo, T.; Mignanelli, M.A. Reactions of Uranium-Plutonium Alloys with Iron. J. Nucl. Sci. Technol. 2001, 38, 112-119. [CrossRef]

75. Nakamura, K.; Kurata, M.; Ogata, T.; Yokoo, T.; Mignanelli, M.A. Phase Relations in the Fe-Pu-U Ternary System. J. Phase Equilib. 2001, 22, 259-264. [CrossRef]

76. Nakamura, K.; Ogata, T.; Kurata, M. Analysis of metal fuel/cladding metallurgical interaction during off-normal transient events with phase diagram of the U-Pu-Zr-Fe system. J. Phys. Chem. Solids 2005, 66, 643-646. [CrossRef]

77. Dwight, A.E.; Mueller, M.H.; Conner, R.A.; Downey, J.W., Jr.; Knott, H. Ternary Compounds with the $\mathrm{Fe}_{2} \mathrm{P}$ type Structure. Trans. Metall. AIME 1968, 242, 2075-2080.

78. Grun, Y.N.; Rogl, P.; Hiebl, K. Structural Chemistry and Magnetic Behaviour of Ternary Uranium Gallides $\mathrm{U}\{\mathrm{Fe}, \mathrm{Co}, \mathrm{Ni}, \mathrm{Ru}, \mathrm{Rh}, \mathrm{Pd}, \mathrm{Os}, \mathrm{Ir}, \mathrm{Pt}\} \mathrm{Ga}_{5}$. J. Less-Common Met. 1986, 121, 497-505. [CrossRef]

79. Tokiwa, Y.; Maehira, T.; Ikeda, S.; Haga, Y.; Yamamoto, E.; Nakamura, A.; Onuki, Y.; Higuchi, M.; Hasegawa, A. Magnetic and Fermi Surface Properties of UFeGa. J. Phys. Soc. Jpn. 2001, 70, 2982-2988. [CrossRef] 
80. Ikeda, S.; Tokiwa, Y.; Okubo, T.; Yamada, M.; Matsuda, T.D.; Inada, Y.; Settai, R.; Yamamoto, E.; Haga, Y.; Onuki, Y. Magnetic and Fermi surface properties of UTGa 5 (T:Fe, Co and Pt). Physica B 2003, 329, 610-611. [CrossRef]

81. Moreno, N.O.; Bauer, E.D.; Sarrao, J.L.; Hundley, M.F.; Thompson, J.D.; Fisk, Z. Thermodynamic and transport properties of single-crystalline $\mathrm{UMGa}_{5}(\mathrm{M}=\mathrm{Fe}, \mathrm{Co}, \mathrm{Ni}, \mathrm{Ru}, \mathrm{Rh})$. Phys. Rev. B 2005, 72, 035119. [CrossRef]

82. Gonçalves, A.P.; Werenborgh, J.C.; Sério, S.; Paixão, J.A.; Godinho, M.; Almeida, M. Structural and magnetic properties of $\mathrm{UFe}_{6} \mathrm{Ga}_{6}$. Intermetallics 2006, 13, 530-536. [CrossRef]

83. Henriques, M.A.; Mora, P.; Cruz, M.M.; Noël, H.; Tougait, O.; Tran, V.H.; Gonçalves, A.P. Crystal structure and magnetic properties of $\mathrm{UFe}_{5} \mathrm{Ga}_{7}$. J. Nucl. Mater. 2009, 389, 160-163. [CrossRef]

84. Ikeda, S.; Okubo, T.; Tokiwa, Y.; Kaneko, K.; Matsuda, T.D.; Yamamoto, E.; Haga, Y.; Onuki, Y. Magnetic properties of $\mathrm{U}_{2} \mathrm{RhGa}_{8}$ and $\mathrm{U}_{2} \mathrm{FeGa}_{8}$. J. Phys. Condens. Matter 2003, 15, S2015-S2018. [CrossRef]

85. Jardin, R.; Colineau, E.; Griveau, J.-C.; Boulet, P.; Wastin, F.; Rebizant, J. A new family of heavy-fermion compounds. J. Alloys Compd. 2007, 432, 39-44. [CrossRef]

86. Couderc, J.J.; Bras, J.; Fagot, F. Precipitation dans le system fer-gallium au voisinage de 25 at. \% Ga. Phys. Status Solidi A 1977, 41, 595-605. [CrossRef]

87. Nishino, Y.; Matsuo, M.; Asano, S.; Kawamiya, N. Stability of the $\mathrm{D0}_{3}$ phase in $\left(\mathrm{FeM}_{1-\mathrm{x}} \mathrm{M}_{\mathrm{x}}\right)_{3} \mathrm{Ga}(\mathrm{M}=3 \mathrm{~d}$ transition metals). Scr. Metall. Mater. 1991, 25, 2291-2296. [CrossRef]

88. Suzuki, T.; Oya, Y.; Ochiai, S. The Mechanical Behavior of Nonstoichiometric Compounds $\mathrm{Ni}_{3} \mathrm{Si}_{1} \mathrm{Ni}_{3} \mathrm{Ge}$ and $\mathrm{Fe}_{3}$ Ga. Metall. Trans. A 1984, 15, 173-181. [CrossRef]

89. Philippe, M.J.; Malaman, B.; Roques, B.; Courtois, A.; Protas, J. Structures cristallines des phases $\mathrm{Fe}_{3} \mathrm{Ga}_{4}$ et $\mathrm{Cr}_{3} \mathrm{Ga}_{4}$. Acta Crystallogr. B 1975, 31, 477-482. [CrossRef]

90. Hausserman, U.; Bostrom, M.; Viklund, P.; Rapp, O.; Bjornangen, T. FeGa 3 and RuGa 3 : Semiconducting intermetallic Compounds. J. Solid State Chem. 2002, 165, 94-99. [CrossRef]

91. Lebech, B.; Wullf, M.; Lander, G.H.; Spirlet, J.C.; Delapalme, A. Neutron diffraction studies of the crystalline and magnetic properties of $\mathrm{UFe}_{2}$. J. Phys. Condens. Mater. 1989, 1, 10229-10248. [CrossRef]

92. Kimball, C.W.; Vaishnava, P.P.; Jorgensen, F.Y. Phonon anomalies and local atomic displacements in the exchange-enhanced superconductor $\mathrm{U}_{6}$ Fe. Phys. Rev. B 1985, 32, 4419-4425. [CrossRef] [PubMed]

93. Ivanov, M.I.; Podol'skaya, N.S. Heats of formation of $\mathrm{U}_{6} \mathrm{Fe}$ and $\mathrm{UFe}_{2}$ Translated from. Soviet. J. Atomic. Energy. 1962, 13, 572-575.

94. Hecker, S.S.; Timofeeva, L.F. A Tale of Two Diagrams; Los Alamos Science: Los Alamos, NM, USA, 2000. 